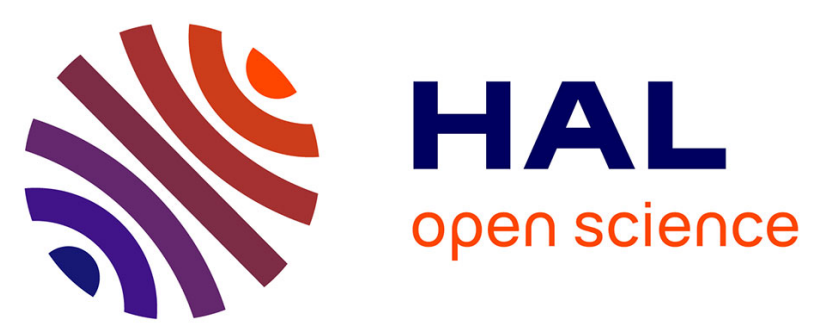

\title{
Nanoencapsulated deltamethrin as synergistic agent potentiates insecticide effect of indoxacarb through an unusual neuronal calcium-dependent mechanism
}

Javier Pitti-Caballero, Laurence Murillo, Olivier List, Guillaume Bastiat, Annie Flochlay-Sigognault, Frank Guerino, Corinne Lefrançois, Nolwenn

Lautram, Bruno Lapied, Véronique Apaire-Marchais

\section{To cite this version:}

Javier Pitti-Caballero, Laurence Murillo, Olivier List, Guillaume Bastiat, Annie Flochlay-Sigognault, et al.. Nanoencapsulated deltamethrin as synergistic agent potentiates insecticide effect of indoxacarb through an unusual neuronal calcium-dependent mechanism. Pesticide Biochemistry and Physiology, 2019, 157, pp.1-12. 10.1016/j.pestbp.2019.03.014 . hal-02413618

\author{
HAL Id: hal-02413618 \\ https://hal.science/hal-02413618
}

Submitted on 25 Oct 2021

HAL is a multi-disciplinary open access archive for the deposit and dissemination of scientific research documents, whether they are published or not. The documents may come from teaching and research institutions in France or abroad, or from public or private research centers.
L'archive ouverte pluridisciplinaire HAL, est destinée au dépôt et à la diffusion de documents scientifiques de niveau recherche, publiés ou non, émanant des établissements d'enseignement et de recherche français ou étrangers, des laboratoires publics ou privés.

\section{(ㄷ)(1) $(5$}

Distributed under a Creative Commons Attribution - NonCommerciall 4.0 International 


\section{Nanoencapsulated deltamethrin as synergistic agent potentiates insecticide effect of indoxacarb through an unusual neuronal calcium-dependent mechanism}

Javier Pitti Caballero ${ }^{a}$, Laurence Murillo ${ }^{b}$, Olivier List ${ }^{a}$, Guillaume Bastiat ${ }^{c}$, Annie Flochlay-Sigognault $^{d}$, Frank Guerino ${ }^{d}$, Corinne Lefrançois ${ }^{a}$, Nolwenn Lautram ${ }^{c}$, Bruno Lapied $^{\mathrm{a}}$, Véronique Apaire-Marchais ${ }^{\mathrm{a}^{*}}$.

aLaboratoire Signalisation Fonctionnelle des Canaux Ioniques et des Récepteurs (SiFCIR), UPRES EA 2647, USC INRA 1330, SFR QUASAV 4207, UFR Sciences Université d'Angers, 2 boulevard Lavoisier, 49045 Angers, cedex, France.

bLIttoral ENvironnement et Sociétés (LIENSs), UMR 7266 CNRS-Université de La Rochelle, Institut du Littoral et de l'Environnement, 2 rue Olympe de Gouges, La Rochelle, France.

"Micro et Nanomédecines Translationnelles, MINT, UNIV Angers, UMR INSERM 1066, UMR CNRS 6021, 4 rue Larrey, 49933 Angers cedex 9, France

dMerck Animal Health, 2 Giralda Farms, Madison, NJ 07940-1026, USA

${ }^{*}$ Corresponding author: Laboratoire SiFCIR, UFR Sciences, 2 boulevard Lavoisier, 49045 Angers, cedex, France ; E-mail adress : veronique.marchais@univ-angers.fr

Keywords: synergistic agent; nanoencasulation; deltamethrin; indoxacarb; insect neurons 


\section{Abstract}

The use of neurotoxic chemical insecticides has led to consequences against the environment, insect resistances and side-effects on non-target organisms. In this context, we developed a novel strategy to optimize insecticide efficacy while reducing doses. It is based on nanoencapsulation of a pyrethroid insecticide, deltamethrin, used as synergistic agent, combined with a non-encapsulated oxadiazine (indoxacarb). In this case, the synergistic agent is used to increase insecticide efficacy by activation of calcium-dependant intracellular signaling pathways involved in the regulation of the membrane target of insecticides. In contrast to permethrin (pyrethroid type I), we report that deltamethrin (pyrethroid type II) produces an increase in intracellular calcium concentration in insect neurons through the reverse $\mathrm{Na} / \mathrm{Ca}$ exchanger. The resulting intracellular calcium rise rendered voltage-gated sodium channels more sensitive to lower concentration of the indoxacarb metabolite DCJW. Based on these findings, in vivo studies were performed on the cockroach Periplaneta americana and mortality rates were measured at $24 \mathrm{~h}, 48 \mathrm{~h}$ and $72 \mathrm{~h}$ after treatments. Comparative studies of the toxicity between indoxacarb alone and indoxacarb combined with deltamethrin or nanoencapsulated deltamethrin (LNCdeltamethrin), indicated that LNC-deltamethrin potentiated the effect of indoxacarb. We also demonstrated that nanoencapsulation protected deltamethrin from esteraseinduced enzymatic degradation and led to optimize indoxacarb efficacy while reducing doses. Moreover, our results clearly showed the benefit of using LNCdeltamethrin rather than piperonyl butoxide and deltamethrin in combination commonly used in formulation. This innovative strategy offers promise for increasing insecticide efficacy while reducing both doses and side effects on non-target organisms. 


\section{Introduction}

Agrochemicals such as neurotoxic insecticides are widely used to improve crop yield and to assure efficient control of insect pests. However, although chemical insecticides are a powerful tool to control insect pests, neurological side-effects and resistance may develop. In the last case, if the same chemical class is used repeatedly and/or if compounds have the same mode of action on targets. This can facilitate cross resistance [1, 2]. Consequently, insecticide resistance management represents a global challenge. Among strategies available, the discovery of new insecticides is always considered as a possible alternative. However, it is a long and expensive process. Usually 9 to 10 years will elapse from discovery to first registration and after registration, the market life for different insecticides varies greatly. In view of these above problems, it is crucial to develop novel strategies based, for example, on the better use of the current insecticides to enhance their efficacy [3]. Different strategies can be proposed including (i) the application of different insecticide combinations acting on different targets (i.e. pyrethroids with other compounds) [4-8] and (ii) the optimization of the effect of insecticides by synergists such as piperonyl butoxide (PBO) and S,S,S-tributyl phosphorotrithioate (DEF) [8-11]. In this case, the mode of action of the majority of synergists is to block the metabolic systems that would otherwise break down insecticide molecules. They interfere with the detoxification of insecticides through their action on enzyme systems involved in the insecticides degradation (e. g., esterases, cytochrome p450 monooxygenases, hydrolases, glutathion S-transferases). However, these strategies do not allow a significant reduction of the active ingredient concentration used. The novel approach we can propose is to use either chemical or biological synergistic 
agents with a given insecticide in combination to optimize insecticide efficacy while reducing doses of the treatment $[7,12]$.

Synergistic agents can be defined as a chemical or biological compound used to enhance the effectiveness of an insecticide although they usually have no or limited effect themselves. At a non-toxic concentration, the synergistic agent is able to activate calcium-dependent intracellular signaling pathways involved in increasing the sensitivity of membrane receptors or ion channels to insecticides. It can thereby produce changes in target conformational states through phosphorylation or dephosphorylation processes $[7,12,13]$. Initial search for patterns of conserved amino acid residues that have been associated with phosphorylation sites in, for instance, voltage-gated sodium channels, GABA receptors and in nicotinic acetylcholine receptor subunits showed that they possess potential phosphorylation sites for protein kinase $A(P K A)$, protein kinase $C$ (PKC) and protein kinase $G$ (PKG) and for calcium/calmodulin-dependent serine/threonine-protein kinase (CaM-kinase) $[7,14-17]$. This is important because it has been demonstrated in insect neurons that intracellular calcium rise modulates, through activation of these molecular events involved in the calcium-dependent signaling pathways, the functional properties of these membrane targets, which thereby increase their sensitivities to insecticides [7, 18-20].

Based on these data, we used deltamethrin as synergistic agent combined to indoxacarb and its activated metabolite DCJW. Deltamethrin is well known to affect voltage-gated sodium channels by i) prolonging the course of the sodium current during depolarization, ii) developping slow tail current and iii) inducing a usedependent block of the action potential coupled with the depolarization of the resting membrane potential [2]. By contrast indoxacarb/DCJW are sodium channel blocker 
insecticides known to block neuronal action potentials in both insect central and peripheral nervous systems. DCJW, is significantly more potent than indoxacarb as an inhibitor of voltage-gated sodium channels in causing hyperpolarizing shifts in the voltage dependence of inactivation (combination of slow and fast inactivation) resulting in the inhibition of the sodium current. Consequently, the aim of our investigation was (i) to demonstrate in vitro that deltamethrin can be used as synergistic agent by potentiating the effect of the indoxacarb metabolite DCJW via an increase of the intracellular calcium concentration in cockroach neurosecretory cells identified as Dorsal Unpaired Median (DUM) neurons and (ii) to evaluate in vivo the synergistic effect of the mixture deltamethrin / indoxacarb by intoxication of the cockroach Periplaneta americana. Furthermore, because nanoencapsulation procedures have shown promising results to increase stability and biodisponibility of the active ingredient [21], deltamethrin was nanoencapsulated to demonstrate if the synergism observed between deltamethrin and indoxacarb can be optimized. In this study, we reveal that reversal of the plasma membrane $\mathrm{Na} / \mathrm{Ca}$ exchanger contributes to the immediate rise in intracellular calcium concentration resulting from voltagegated sodium channel modulation induced by deltamethrin. This elevation of intracellular calcium concentration renders the sodium channels more sensitive to DCJW. Based on these in vitro studies, we have also develop a novel strategy using deltamethrin-loaded lipid nanocapsules (LNC-deltamethrin) to perform in vivo toxicological studies with LNC-deltamethrin / indoxacarb in combination in order to increase indoxacarb efficacy while reducing its concentrations and negative impact on the environment. 


\section{Materials and methods}

\subsection{In vitro studies}

\subsubsection{Biological model}

All experiments were performed on adult male cockroaches Periplaneta americana taken from our laboratory stock colony and reared under standard conditions $\left(29^{\circ} \mathrm{C}\right.$, photocycle of $12 \mathrm{~h}$ light $/ 12 \mathrm{~h}$ dark). Animal care and handling procedures were in accordance with French institutional and national health guidelines.

\subsubsection{Insecticides and pharmacological products}

Permethrin was provided by Intervet Productions s.a., (Igoville, France). Deltamethrin was purchased from Sigma Aldrich (Saint Quentin Fallavier, France). Stock solutions of both components $\left(10^{-2} \mathrm{M}\right)$ were prepared in dimethylsulfoxide (DMSO) (Sigma-Aldrich), and stored at $-20^{\circ} \mathrm{C}$. Subsequent dilutions of deltamethrin $\left(10^{-4} \mathrm{M}\right.$ to $\left.10^{-7} \mathrm{M}\right)$ were prepared in sucrose (Sigma-Aldrich) syrup $100 \mathrm{mg} \mathrm{mL}^{-1}$. For in vivo studies, the highest concentration of DMSO used for toxicity experiments was $0.1 \%$. For in vitro, the concentration of solvent $(0.1 \%)$ was found to be without effect on the electrical activity of DUM neurons.

Indoxacarb (Avaunt ${ }^{\circledR}$ 15\% Emulsion Concentrate $(E C)$ ) was supplied by DuPont ${ }^{\mathrm{TM}}$ and diluted (1/28) in sucrose syrup $100 \mathrm{mg} \mathrm{mL}^{-1}$ to obtain a stock solution at $10^{-2} \mathrm{M}$. Subsequent dilutions of indoxacarb $\left(10^{-3} \mathrm{M}\right.$ to $\left.10^{-7} \mathrm{M}\right)$ were prepared in sucrose syrup $100 \mathrm{mg} \mathrm{mL}^{-1}$ for the cockroach exposure experiments. The indoxacarb metabolite decarbomethoxylated JW062 (DCJW) was provided by DuPont Crop Protection Stine Haskell Research Center Newark, USA. Stock solution (10 mM) was prepared in DMSO. 
Piperonyl butoxide (PBO) (Sigma-Aldrich) which is a well-known inhibitor of cytochrome-P450 monooxygenases was prepared in DMSO to obtain a stock solution at $500 \mu \mathrm{g} / \mathrm{mL}$.

\subsubsection{Cell preparation}

Experiments were carried out on DUM neuron somata isolated from the midline of the terminal abdominal ganglion (TAG) of the nerve chord of adult male cockroaches (Periplaneta americana). Animals were immobilized ventral side up on a dissection dishes. The ventral cuticle and the accessory gland were removed to allow access to the TAG, which was carefully dissected under a binocular microscope and placed in normal cockroach saline containing $200 \mathrm{mM} \mathrm{NaCl}, 3.1 \mathrm{mM} \mathrm{KCl}, 5 \mathrm{mM}$ $\mathrm{CaCl}_{2}, 4 \mathrm{mM} \mathrm{MgCl}$, $10 \mathrm{mM}$ HEPES, $50 \mathrm{mM}$ sucrose, $\mathrm{pH}$ was adjusted to 7.4 with $\mathrm{NaOH}$. Isolation of adult DUM neuron somata was performed under sterile conditions using enzymatic treatment and mechanical dissociation of the median part of the TAG, as previously described [22]. DUM neuron somata were maintained at $29^{\circ} \mathrm{C}$ for 24h before electrophysiological experiments were carried out.

\subsubsection{Whole-Cell Recordings}

The whole-cell patch-clamp recording configuration was used to record voltage-dependent inward sodium currents (voltage-clamp mode) at room temperature $\left(20-22^{\circ} \mathrm{C}\right)$. Patch pipettes were pulled from borosilicate glass capillary tubes (GC 150T-10; Clark Electromedical Instruments, Harvard Apparatus, Edenbridge, UK) with a PP83 puller (Narishige, Tokyo, Japan). Pipettes had a resistance ranging from 0.9 to $1.1 \mathrm{M} \Omega$ when filled with internal solution containing 90 mM CsCl, 70 mM CsF, 15 mM NaCl, 1 mM MgCl2, 2 mM ATP-Mg, 5 mM EGTA, 10 
mM HEPES, pH was adjusted to 7.4 with $\mathrm{CsOH}$. The superfusing solution contained $100 \mathrm{mM} \mathrm{NaCl}, 100 \mathrm{mM}$ Tetraethylammonium-chloride (TEA-Cl), $3.1 \mathrm{mM} \mathrm{KCl}, 2 \mathrm{mM}$ $\mathrm{CaCl}_{2}, 7 \mathrm{mM} \mathrm{MgCl}$, $0.5 \mathrm{mM} \mathrm{CdCl}$, $3 \mathrm{mM}$ 4-aminopyridine (4-AP), $10 \mathrm{mM}$ HEPES, $\mathrm{pH}$ was adjusted to 7.4 with TEA-OH. Both superfusing solution and internal pipette solution used to record inward sodium currents were designed to eliminate any interference from calcium and potassium currents as already described elsewhere $[23,24]$.

The liquid junction potential between bath and internal solution was always corrected before the formation of a gigaohm seal ( $>2 G \Omega$ ). Voltage-dependent sodium currents were recorded with an Axopatch 200A (Molecular Devices, Sunnyvale, CA) amplifier, filtered at $5 \mathrm{kHz}$ using a 4-pole low-pass Bessel filter. Series resistance value was obtained for each experiment from the patch-clamp amplifier settings after compensation and varied between 1.5 and $3 \mathrm{M} \Omega$. Step voltage pulses were generated by a programmable stimulator (SMP 310; Biologic, Claix, France) or an IBM computer with software control pClamp 8.0.3 connected to a 125$\mathrm{kHz}$ labmaster DMA data acquisition system (TL-1; Axon Instruments). The pClamp package (version 8.0.3) was used for data acquisition and analysis. DUM neuron cell bodies were voltage-clamped at a steady-state holding potential of $-90 \mathrm{mV}$, and 30 ms test pulses (except when otherwise stated) were applied at a frequency of $0.1 \mathrm{~Hz}$. Although leak and capacitive currents were compensated electronically at the beginning of each experiment, subtraction of residual capacitive and leakage currents was performed with an online $\mathrm{P} / 6$ protocol provided by pClamp. All compounds were purchased from Sigma Aldrich. 


\subsubsection{Calcium imaging}

For calcium imaging experiments, DUM neuron cell bodies were isolated from the TAG of adult male cockroaches, as already described above. The cells were washed two times in saline and incubated in the dark with $5 \mathrm{mM}$ Fura-2 pentakis (acetoxy-methyl) ester (Fura-2 AM) (Sigma-Aldrich) in the presence of $0.1 \%$ pluronic acid F68 (Sigma- Aldrich) for $1 \mathrm{~h}$ at $37^{\circ} \mathrm{C}$. After loading, cells were washed two times in saline. The glass coverslips were then mounted in a recording chamber (Warner Instruments, Hamden, CT, USA) connected to a gravity perfusion system allowing drug application. Imaging experiments were performed with an inverted Nikon Eclipse Ti microscope (Nikon, Tokyo, Japan) equipped with epifluorescence. Excitation light was provided by a $75-\mathrm{W}$ integral xenon lamp. Excitation wavelengths $(340 \mathrm{~nm}$ and $380 \mathrm{~nm}$ ) were applied using a Lamdba DG4 wavelength switcher (Sutter instrument, Novato, CA, USA). Images were collected with an Orca-R2 CCD camera (Hamamatsu photonics, Shizuoka, Japan) and recorded on the computer with Imaging Workbench software (version 6, Indec BioSystems, Santa Clara, CA, USA). Experiments were carried out at room temperature. Intracellular calcium level was expressed as the ratio of emitted fluorescence $(340 / 380 \mathrm{~nm})$.

\subsubsection{Statistical analysis}

For statistical analysis, normal distribution (or Gaussian distribution) of the data was tested using Kolmogorov-Smirnov at a significance of $p<0.05$ [25] and R software ( $R$ version 2.9.0 Software). Because Gaussian distributions of data were obtained, the one way ANOVA had to be used (parametric statistical method) followed by the post-hoc Bonferroni's test. Significant differences were considered for $\mathrm{p}<0.05$. 
2.2. Formulation of lipid nanocapsules, deltamethrin-loaded lipid nanocapsules and their characterization

\subsubsection{Preparation of lipid nanocapsules and deltamethrin-loaded lipid nanocapsules}

Non-loaded and deltamethrin-loaded lipid nanocapsules (LNC and LNC-deltamethrin, respectively) formulation processes were based on an already reported phaseinversion method [26-28]. Briefly, 846 mg of Kolliphor ${ }^{\circledR}$ HS 15 (non-ionic surfactant, a mixture of free polyethylene glycol 660 and polyethylene glycol 660 hydroxystearate) (provided by BASF, Ludwigshafen, Germany); 75 mg of Lipoid ${ }^{\circledR} 75-3$ (soybean lecithin at a $69 \%$ concentration of phosphatidylcholine) (supplied by Lipoïd $\mathrm{GmbH}$, Ludwigshafen, Germany); 1028 mg of Labrafac ${ }^{\circledR}$ WL 1349 (capric/caprylic acid triglyceride) (provided by Gattefossé S.A., Saint-Priest, France); $89 \mathrm{mg}$ of $\mathrm{NaCl}$ (purchased from Prolabo, Fontenay-Sous-Bois, France); and $2962 \mathrm{mg}$ of de-ionised water (from a Milli ${ }^{\circledR} \mathrm{Q}$ system, Millipore, Billerica, MA, USA) were precisely weighed. Under continuous agitation (magnetic stirring), the mixture was heated up to $95^{\circ} \mathrm{C}$ and cooled down to $60^{\circ} \mathrm{C}$ three times. During the last temperature decrease step, at around $75^{\circ} \mathrm{C}, 5 \mathrm{~mL}$ of de-ionized cold water (at $4^{\circ} \mathrm{C}$ ) were quickly added, leading to the suspension of LNC. For LNC-deltamethrin, deltamethrin was first dissolved in Labrafac $^{\circledR}$ WL 1349 at a concentration of $0.1 \%(w / w)$, before adding the other constituents and to proceed to the formulation process. LNC and LNC-deltamethrin suspensions were stored at $4^{\circ} \mathrm{C}$.

2.2.2. Size distribution of lipid nanocapsules and deltamethrin-loaded lipid nanocapsules

The size distribution, i.e. hydrodynamic diameter (Z-ave) and polydispersity index (Pdl), of both LNC and LNC-deltamethrin was measured using a Zetasizer ${ }^{\circledR}$ Nano ZS 
(Malvern Instrument Ltd., Worcestershire, UK). The quasi-elastic light scattering instrument is equipped with a $4 \mathrm{~mW}$ Helium-Neon laser, with an output wavelength of $633 \mathrm{~nm}$, and a scatter angle fixed at $173^{\circ}$. The correlation functions were fitted using an exponential fit (Cumulant approach) for Z-ave and Pdl determinations. All measurements were performed at $25^{\circ} \mathrm{C}$ on LNC suspensions diluted in de-ionized water by a factor of $60(\mathrm{v} / \mathrm{v})$.

\subsubsection{Deltamethrin encapsulation efficiency and analysis method}

Two basic purification processes of LNC-deltamethrin suspension were used: centrifugation (10,000 g during $10 \mathrm{~min})$ and filtration $(0.22 \mu \mathrm{m})$, to remove free solid micro-aggregates of deltamethrin in aqueous suspension. The deltamethrin encapsulation rate in LNC was determined before and after the purification processes.

Fifty $\mu \mathrm{L}$ of non-purified or purified LNC-deltamethrin were mixed with $950 \mu \mathrm{L}$ of methanol. The mixtures were vigorously vortexed to dissolve the LNCs, destroying their structure and allowing to the release of deltamethrin, soluble in methanol. These solutions were filtered $(0.22 \mu \mathrm{m})$ before the titration of deltamethrin, performed using an UPLC system (Waters, France). A C18 analytical column (ACQUITY UPLC ${ }^{\circledR}$ BEH C18 $1.7 \mu \mathrm{m} 2.1 \times 50 \mathrm{~mm}$, Waters, France) was used at $40^{\circ} \mathrm{C}$. The mobile phase consisted of Acetonitrile:Water mixture. A succession of gradient and isocratic programs was applied: gradient from $0.7: 0.3$ to $1: 0(\mathrm{v} / \mathrm{v})$ between 0 and $1 \mathrm{~min}$; isocratic 1:0 $(v / v)$ until 2 min; gradient from 1:0 to 0.7:0.3 $(v / v)$ between 2 and $3 \mathrm{~min}$; and isocratic 0.7:0.3 $(\mathrm{v} / \mathrm{v})$ until $5 \mathrm{~min}$. The flow rate was $0.4 \mathrm{~mL} / \mathrm{min}$, the injection volume was $5 \mu \mathrm{L}$ and deltamethrin was quantified (retention time: $1.65 \mathrm{~min}$ ) by an UV detector at $\lambda=266 \mathrm{~nm}$. The calibration curve was established by quantifying the area 
under the curves (AUCs) of deltamethrin solutions (50 $\mu \mathrm{L}$ of LNC suspension and $950 \mu \mathrm{L}$ of deltamethrin in methanol) with final deltamethrin concentration range from 0 to $5 \mu \mathrm{g} / \mathrm{mL}$.

The encapsulation efficiencies (EE) of deltamethrin (DLT) in LNCs, before and after the purification processes, were calculated using the following equation:

$$
\mathrm{EE}(\%)=\frac{\text { Experimental DLT amount in LNCs } \times 100}{\text { Theoretical DLT amount in LNCs }}
$$

\subsubsection{Enzymatic protection}

One $\mathrm{mL}$ of LNC-deltamethrin suspension was mixed with $50 \mu \mathrm{L}$ of esterase in water (Esterase from porcine liver, Sigma-Aldrich, France) $(\mathrm{pH}=8.3)$. In addition, $20 \mu \mathrm{L}$ of deltamethrin in DMSO was mixed with $980 \mu \mathrm{L}$ of water and $50 \mu \mathrm{L}$ of esterase in water $(\mathrm{pH}=8.3)$. Deltamethrin concentration was $95 \mu \mathrm{g} / \mathrm{mL}$ and esterase concentration was $0.52 \mu \mathrm{g} / \mathrm{mL}(0.009 \mathrm{U} / \mathrm{mL})$. Under magnetic stirring at room temperature, $50 \mu \mathrm{L}$ of the each mixture were sampled at $5 \mathrm{~min}, 30 \mathrm{~min}, 1 \mathrm{~h}, 1 \mathrm{~h} 30,2 \mathrm{~h}, 3 \mathrm{~h}, 4 \mathrm{~h}, 6 \mathrm{~h}$ and $24 \mathrm{~h}$, and completed with $950 \mu \mathrm{L}$ of methanol. Deltamethrin was quantified using UPLC method (See section 2.2.3).

\subsection{In vivo studies: exposure to insecticides}

\subsubsection{Intoxication protocol}

In vivo studies were performed using between 4 and 17 experimental groups of 10 adult cockroaches per concentration of insecticide. Before starting the experiments, cockroaches were deprived of access to water for 48 hours in order that they may drink the whole insecticide supplied. The different concentrations of insecticides were administered by ingesting (orally intoxication). Thus $10 \mu \mathrm{L}$ of insecticide or $20 \mu \mathrm{L}$ of the mixture of insecticides (i.e., $10 \mu \mathrm{L}$ synergistic agent and 10 
$\mu \mathrm{L}$ insecticide) were deposited on parafilm $\mathrm{M}^{\circledast}$ and absorbed by each cockroach. After insecticide treatment, cockroaches were put back in their vivarium. Control experiments were performed under the same experimental conditions without insecticide and with LNCs. Parallel experiments were performed with PBO used at a maximal sublethal dose (50 $\mu \mathrm{g} / \mathrm{cockroach})$. PBO was added to deltamethrin alone or to deltamethrin in combination with indoxacarb.

Mortality rate was assessed $24 \mathrm{~h}, 48 \mathrm{~h}$ and $72 \mathrm{~h}$ after the treatment. The mortality criteria were based on the daily observation of the appearance of cockroaches. Cockroaches affected by insecticide were considered "dead" when they turn and do not present any type of movement of their extremities. Mortality of the cockroaches was observed pressing on the abdomen for one minute and the death is recorded in absence of movement.

\subsubsection{Data analysis}

To estimate the $\mathrm{EC}_{50}$ values of the curve fitting, data were analyzed with the GraphPad Prism version 5.0 (GraphPad Software, La Jolla, CA, USA). The Hill equation used to fit the sigmoid curve was:

$$
Y=\text { Bottom }+\frac{(\text { Top-Bottom })}{1+10^{(\text {LogEC } 50-X) \text { Hillslope }}}
$$

where Top and Bottom are plateaux in the units of the $Y$ axis, EC50 is the concentration that gives halfway between Bottom and Top. HillSlope describes the steepness of the curve. All statistical analysis were performed with Mann-Whitney test (non-parametric statistical method) (using GraphPad Prism version 5.0 (GraphPad Software, La Jolla, CA, USA). Significant differences were considered for $p<0.05$. 
The combination index $(\mathrm{Cl})$ method [29] was used to evaluate possible synergistic interaction between deltamethrin / indoxacarb and LNC-deltamethrin / indoxacarb. To assess synergisms, antagonism and/or additive effect, the combination index was determined by using the following equation:

$$
C I x=\frac{L C x^{1 m}}{L C x^{1}}+\frac{L C x^{2 m}}{L C x^{2}}+\left(\frac{L C x^{1 m}}{L C x^{1}} \times \frac{L C x^{2 m}}{L C x^{2}}\right)
$$

Where the values in the numerator of the equation are the lethal concentrations (LC) of insecticides 1 and 2 in mixture giving $x$ mortality. $L C_{x}{ }^{1}$ and $L C_{x}{ }^{2}$ are the lethal concentrations of insecticides 1 and 2 respectively, producing the same mortality $x$ when used alone. The resultant values of $\mathrm{Cl}$ were scaled to categorize the mixture effect: additive effect when $\mathrm{Cl}=1$, antagonist effect when $\mathrm{Cl}>1$ and synergistic effect when $\mathrm{Cl}<1$. These values were calculated at $20 \%$ mortality level.

\section{Results}

3.1. Differential effects of two pyrethroids, deltamethrin and permethrin on isolated DUM neuron cell body intracellular calcium concentration.

The first set of experiments was designed to investigate the effect of deltamethrin (Fig. $1 \mathrm{~A}$ ) on $\left[\mathrm{Ca}^{2+}\right]$. Bath application of $10^{-6} \mathrm{M}$ deltamethrin on Fura-2 loaded DUM neuron cell body produced a marked elevation in $\left[\mathrm{Ca}^{2+}\right]$ i followed by a sustained elevated level (Fig. 2Aa). Maximum calcium rise occured approximately 450s upon application of the insecticide (Fig. 2B). It is interesting that similar experiments performed in cell bodies pretreated with permethrin $\left(10^{-6} \mathrm{M}\right)$ (Fig. 1B) did not produce elevation of $\left[\mathrm{Ca}^{2+}\right]_{i}$ (Fig. 2Ab, B). We next examined the source of the intracellular calcium rise observed with deltamethrin. When the experiments were conducted in the presence of the well-known inorganic calcium channel blocker $\mathrm{CdCl}_{2}\left(5.10^{-4} \mathrm{M}\right)$, the elevation in $\left[\mathrm{Ca}^{2+}\right]$ induced by deltamethrin was not affected (Fig. 3Aa, Ba). By 
contrast, external application of the sodium channel blocker TTX $\left(10^{-7} \mathrm{M}\right)$ completely suppressed the intracellular calcium rise triggered by deltamethrin (Fig. 3Aa, Bb). Careful observation of the calcium response produced by $10^{-6} \mathrm{M}$ deltamethrin revealed that the time course $\left[\mathrm{Ca}^{2+}\right]$ i rise differed according to the cell region (Fig. 3B). As indicated in Fig. 3B, illustrating the three-dimensional cytofluorescence intensity plot, the elevation in $\left[\mathrm{Ca}^{2+}\right] \mathrm{i}$ was first detected at the cell body periphery whereas in the middle part of the cell there was no fluorescence detected. Because bath application of $\mathrm{CdCl}_{2}$ failed to reduce the elevation of $\left[\mathrm{Ca}^{2+}\right]_{i}$ induced by deltamethrin (Fig. 3Ba) whereas TTX completely abolished intracellular calcium rise (Fig. 3Bb), it seemed that the deltamethrin-induced increase $\left[\mathrm{Ca}^{2+}\right]$ involved an unexpected membrane mechanism. It is known that deltamethrin, a type II pyrethroid, causes membrane depolarization accompanied by suppression of the action potential [30]. However, the expected participation of voltage-gated calcium channels activated by membrane depolarization and suspected to be involved in calcium influx into the cell body was eliminated since the calcium channel blocker $\mathrm{CdCl}_{2}$ did not reduce $\left[\mathrm{Ca}^{2+}\right]_{i}$ rise produced by deltamethrin (Fig. 3Aa,b). In addition, because pyrethroids cause prolonged opening of voltage-gated sodium channels, by inhibiting deactivation and stabilizing the open state, it is tempting to suggest that deltamethrin could produce an increase in intracellular sodium concentration through its effect on voltage-gated sodium channels (see Fig. 3Aa, Bb), which thereby could activate the reverse mode of the $\mathrm{Na}^{+} / \mathrm{Ca}^{2+}$ (NCXrev) exchanger to uptake calcium. In other words, deltamethrin, via the reverse NCX mode, could induce a net calcium gain coupled to the extrusion of sodium. To substantiate this hypothesis, Kb-R7943, the well-known inhibitor of the NCXrev was tested. As shown in Fig. 3Ab, Bc, the enhancement of 
$\left[\mathrm{Ca}^{2+}\right]_{i}$ in response to deltamethrin was completely abolished after $5.10^{-6} \mathrm{M} \mathrm{Kb}-\mathrm{R} 7943$ pretreatment.

3.2. Synergism between deltamethrin and DCJW occurs through $\left[\mathrm{Ca}^{2+}\right]_{i}$ rise in DUM neurons

Previous findings performed on isolated DUM neuron cell bodies indicated that DCJW, the decarbomethoxylated metabolite of the oxadiazine insecticide indoxacarb (Fig. 1C), blocks voltage-dependent sodium channels [31]. In addition, under the same experimental conditions, we demonstrated that calcium-dependent intracellular regulation of voltage-gated sodium current increases the sensitivity to DCJW [19]. Based on these results, we were interested in studying the putative synergistic effect of pyrethroids, deltamethrin and permethrin on the blocking action of DCJW using the patch-clamp technique in the whole-cell recording configuration under voltage-clamp mode. According to results presented in Fig. 2 and to ensure that permethrin was ineffective to produce synergistic effect, a higher concentration of permethrin was tested. As illustrated in Fig. 4A, bath application of permethrin $\left(10^{-5} \mathrm{M}\right)$ and DCJW (10${ }^{7} \mathrm{M}$ ) applied in combination on DUM neurons pretreated with permethrin $\left(10^{-5} \mathrm{M}\right)$ did not produce any significant increase of the DCJW-induced blocking effect of the voltage-dependent sodium current amplitude elicited by a 30-ms depolarizing pulse to $0 \mathrm{mV}$ from a holding potential of $-90 \mathrm{mV}$, compared to those obtained with the insecticides applied alone $(F(2,16)=1.8, p=0.19)$. By contrast, co-application of deltamethrin $\left(3.10^{-6} \mathrm{M}\right)$ with DJCW $\left(10^{-7} \mathrm{M}\right)$ on DUM neurons pretreated with deltamethrin $\left(3.10^{-6} \mathrm{M}\right)$ resulted in an important synergistic effect of DCJW on the voltage-dependent sodium current amplitude (Fig. 4B) $(F(2,14)=16.5, p=0.0002)$. To express more quantitatively the synergism of between deltamethrin and DCJW, 
isolated DUM neurons were exposed to various concentrations of DCJW. The semilogarithmic concentration-response curve for the blockade of sodium current obtained after 20 minutes of treatment with DCJW $\left(10^{-7} \mathrm{M}\right)$ used alone and combined with deltamethrin (concentration range from $10^{-7} \mathrm{M}$ to $10^{-5} \mathrm{M}$ ) to determine the minimum concentration of deltamethrin necessary to obtain the maximum potentiation of DCJW effect. As illustrated in Fig. 4C, the minimum deltamethrin concentration needed to strongly increase the effect of DCJW (used at $10^{-7} \mathrm{M}$ ) was determined to be $3.10^{-6} \mathrm{M}$. In other words, when the minimum deltamethrin concentration was used (i.e., $3.10^{-6} \mathrm{M}$ ), the maximum effect of DCJW was obtained for a concentration more than 10-fold lower (arrow in Fig. 4C).

\subsection{Determination of the lowest concentration of deltamethrin used as synergistic} agent in cockroaches Periplaneta americana

Based on the results obtained in vitro, presented just above and to investigate in vivo the expected synergism between these two compounds, we first examined the effect of deltamethrin alone in adult cockroaches Periplaneta americana. A second set of experiments was performed with indoxacarb tested alone and combined with deltamethrin. Indoxacarb, in vivo, is bioactivated by the cleaving of a carbomethoxy group from the parent compound, occurring through the action of esterase and/or amidase enzymes. In this case, the released $\mathrm{N}$-decarbomethoxylated metabolite DCJW produces toxic effects via an inhibition of voltage-gated sodium channels [32].

In order to determine the lowest concentration of deltamethrin producing mortality of adults Periplaneta americana, the average mortality rate percentages were plotted against the logarithm of the non-cumulative concentrations of deltamethrin, at $24 \mathrm{~h}, 48 \mathrm{~h}$ and $72 \mathrm{~h}$ after receiving deltamethrin (Fig. 5A,B,C). In each 
case, the sigmoid curve corresponded to the best fit (Table 1) according to the Hill equation (2). The EC50 estimated for deltamethrin (i.e., the concentration of deltamethrin that produces $50 \%$ mortality) at $24 \mathrm{~h}, 48 \mathrm{~h}$ and $72 \mathrm{~h}$ were presented in Table 1 . The threshold concentration inducing mortality was $10^{-5} \mathrm{M}$ at $24 \mathrm{~h}, 48 \mathrm{~h}$ and $72 \mathrm{~h}$. The slopes were equally reproducible for $24 \mathrm{~h}$ and $48 \mathrm{~h}$ whereas the slope of the curve measured at $72 \mathrm{~h}$ was initially not as steep as $24 \mathrm{~h}$ and $48 \mathrm{~h}$ (Table 1 ). This suggested that at $72 \mathrm{~h}$, the effect of increasing deltamethrin concentration was relatively minimal, whereas the steeper slopes measured at $24 \mathrm{~h}$ and $48 \mathrm{~h}$ suggested that maximum efficacy was obtained in a narrow range of concentrations of deltamethrin. In addition, the maximum effect reached changed versus time of exposure from $58 \pm 12 \%$ at $24 h(n=17)$ to $91 \pm 7 \%(n=18)$ and $98 \pm 3(n=11)$ at $48 h$ and $72 h$, respectively. The following sequence of efficacy was $24 h<48 h<72 h$ (Fig. $5 A, B, C)$. Then, we were interested in performing comparative studies of the toxicity induced by deltamethrin and indoxacarb, used alone and in combination. Adult male cockroaches Periplaneta americana were fed individually with different concentrations of indoxacarb (from $10^{-7} \mathrm{M}$ to $10^{-5} \mathrm{M}$ ) tested alone and with deltamethrin $\left(10^{-6} \mathrm{M}\right.$ and $\left.10^{-5} \mathrm{M}\right)$ in combination. The two concentrations of deltamethrin were chosen according to the results illustrated in Fig. $2 A$ and $5 A, B, C$. A group bar chart was used at $24 \mathrm{~h}, 48 \mathrm{~h}$ and $72 \mathrm{~h}$ to compare data : deltamethrin $\left(10^{-5} \mathrm{M}\right)$ / indoxacarb mixtures vs indoxacarb alone, and deltamethrin $\left(10^{-6} \mathrm{M}\right)$ / indoxacarb mixtures vs indoxacarb alone (Fig. 5D,E,F). While no difference was observed after 24h exposure (Fig. 5D), the percentage of mortality rates were significantly increased with deltamethrin $\left(10^{-6} \mathrm{M}\right)$ / indoxacarb $\left(10^{-5} \mathrm{M}\right)$ mixture at $48 \mathrm{~h}(\mathrm{U}(8,8)=13.0$, $\mathrm{p}=0.0324$; Fig. 5E) and statistically more potentiated with deltamethrin $\left(10^{-6} \mathrm{M}\right) /$ 
indoxacarb $\left(10^{-5} \mathrm{M}\right)$ mixture at $72 \mathrm{~h}(\mathrm{U}(8,8)=8.0, \mathrm{p}=0.0078$; Fig. $5 \mathrm{~F})$, compared to indoxacarb used alone.

3.4. Comparative studies of the toxicity between deltamethrin and nanoencaspulateddeltamethrin

It is well known that among detoxification enzymes, esterases and cytochrome P450s are responsible for deltamethrin metabolism. However, in our context, deltamethrin is proposed to be used as synergistic agent capable of optimizing indoxacarb efficacy through intracellular calcium rise. Consequently, to avoid rapid metabolization of deltamethrin by a hydrolytic cleavage of the ester bond followed by oxidation yielding the non-active acid metabolites, additional set of experiments were designed to comparatively evaluate mortality rates of deltamethrin used alone, deltamethrin in combination with PBO and nanoencapsulated deltamethrin (Fig. 6A). Since PBO shows a role in blocking enzymes involved in detoxifying deltamethrin, mortality rates measured at $24 \mathrm{~h}, 48 \mathrm{~h}$ and $72 \mathrm{~h}$ after $10^{-5} \mathrm{M}$ deltamethrin + PBO mixture were expected to increase. As illustrated in the Fig. 6A, the comparative histograms representing mortality rates versus time of exposure indicated that the combination of $10^{-5} \mathrm{M}$ deltamethrin with PBO was more effective in mortality rate of cockroaches than deltamethrin alone $(U(9,17)=24.0, \quad \mathrm{p}=0.0017 ; \quad \mathrm{U}(9,17)=9.0, \quad \mathrm{p}=0.0001 ; \quad$ and $U(4,9)=1.0, p=0.0104$ at $24 \mathrm{~h}, 48 \mathrm{~h}$ and $72 \mathrm{~h}$, respectively). These results indicated that the presence of synergist has led to a decrease in detoxification therefore resulting in higher mortality rate from the beginning of treatment (i.e., $24 \mathrm{~h}$ ) and after $48 \mathrm{~h}$ and $72 \mathrm{~h}$, in comparison with absence of PBO.

We then performed additional experiments to propose that nanoencapsulated deltamethrin helped in delivering higher impact on cockroaches than deltamethrin + 
PBO mixture. Deltamethrin was encapsulated in lipid nanocapsules (LNCdeltamethrin) using a phase inversion process, already described in the literature [2628]. Deltamethrin was solubilized in the triglyceride core of the LNCs. After the formulation process, the size of LNCs (Z-Ave) was measured at $57 \pm 3 \mathrm{~nm}(\mathrm{n}=6)$, with a monomodal and monodisperse size distribution: $\mathrm{Pdl}=0.07 \pm 0.01(\mathrm{n}=6)$. In addition, a total deltamethrin encapsulation rate was estimated, using UPLC for the non-purified formulation and calculated according to equation (1), at $99 \pm 3 \%(n=3)$, but also the purified ones: filtration over $0.22 \mu$ m estimated at $104 \pm 1 \%(n=3)$, or centrifugation at $10,000 \mathrm{~g}$ during $10 \mathrm{~min}$ at $103 \pm 2 \%(\mathrm{n}=3)$. It should be noted that the size distributions of the LNC-deltamethrin were not modified after purification. To investigate the potential higher toxicity of nanoencapsulated deltamethrin in cockroaches, the effects of deltamethrin alone and LNC-deltamethrin were compared (Fig. 6). Cockroaches were fed orally with $10 \mu \mathrm{L}$ of deltamethrin and others with 10 $\mu \mathrm{L}$ of $\mathrm{LNC}$-deltamethrin. Deltamethrin concentrations ranging from $10^{-7} \mathrm{M}$ to $10^{-4} \mathrm{M}$ were tested and mortality rates were evaluated at $24 \mathrm{~h}, 48 \mathrm{~h}$ and $72 \mathrm{~h}$ after treatment. As shown in Fig. 6B,C,D, the data for deltamethrin alone were compared with the concentration-dependent actions of LNC-deltamethrin. The concentration-response curves established for LNC-deltamethrin and corresponded to the best fit according to the Hill equation (2) were fundamentally different from those obtained with deltamethrin alone in term of potency, maximal efficacy and slope at $24 \mathrm{~h}, 48 \mathrm{~h}$ and 72h. In each case, the threshold concentration at which toxicity first appeared was lower than that of evaluated with deltamethrin alone. Moreover, from that point, the curve increased with higher concentration levels with substantial changes in the shape and slope of the sigmoïd curves. The corresponding EC 50 estimated at 24, 48 and 72 hours were lower (i.e., $1.710^{-5} \mathrm{M}, 2.10^{-5} \mathrm{M}$ and $7.10^{-6} \mathrm{M}$, respectively) than 
those obtained with deltamethrin alone (Table 1). The relatively flat concentrationresponse curves observed with LNC-deltamethrin (Hill slopes were 1.9, 1.1 and 0.9 at $24 \mathrm{~h}, 48 \mathrm{~h}$ and $72 \mathrm{~h}$, respectively) compared to the Hill slope values determined with deltamethrin (Table 1), indicated important changes in the percentage of the mortality rates obtained when the concentration increased. Although LNC-deltamethrin produced weak toxicity at $24 \mathrm{~h}$, these results demonstrated that LNC-deltamethrin had stronger toxicity than deltamethrin alone at $48 \mathrm{~h}$ and $72 \mathrm{~h}$ (e.g., $\cup(6,17)=4.5$, $p=0.0006$; and $U(4,5)=0.0, p=0.0189$ for $10^{-5} \mathrm{M}$ for $48 \mathrm{~h}$ and $72 \mathrm{~h}$, respectively). In fact this increased toxicity produced by LNC-deltamethrin formulation could be related to its slow releasing properties with enhanced permeability and/or stability. These properties could be mainly achieved through either protecting the nanoencapsulated active deltamethrin from premature degradation and/or metabolization or increasing efficacy for a longer period (see Fig. 6C,D). This last point being fundamental since deltamethrin was expected to play a key role as synergistic agent to produce intracellular calcium rise necessary to optimize indoxacarb efficacy on voltage-gated sodium channels through esterase-induced bioactivation to its more active metabolite DCJW.

3.5. Comparative studies of the toxicity of deltamethrin / indoxacarb and LNCdeltamethrin / indoxacarb mixtures.

The following experiments were designed to investigate the efficacy of LNCdeltamethrin / indoxacarb mixture. Fig. 7 shows mortality rates of cockroaches exposed to indoxacarb tested alone at different concentrations (from $10^{-7} \mathrm{M}$ to $10^{-5} \mathrm{M}$ ), deltamethrin $\left(10^{-6} \mathrm{M}\right)+$ indoxacarb and LNC-deltamethrin $\left(10^{-6} \mathrm{M}\right)+$ indoxacarb at $24 \mathrm{~h}, 48 \mathrm{~h}$ and $72 \mathrm{~h}$. At $24 \mathrm{~h}$, mortality rate was not significantly higher with both 
mixtures compared to indoxacarb alone (Fig. 7A). At 48h, mortality rate reached $24 \pm 10 \%(\mathrm{U}(9,10)=9.5, p=0.0039)$ with LNC-deltamethrin $\left(10^{-6} \mathrm{M}\right)+$ indoxacarb $\left(10^{-}\right.$ $\left.{ }^{6} \mathrm{M}\right)$ mixture (Fig. 7B). The treatment with this mixture consistently and significantly achieved the highest level of mortality at $72 \mathrm{~h}$ with indoxacarb used at $10^{-6} \mathrm{M}$ $(40 \pm 14 \%, U(9,10)=12.5, p=0.0084)$, compared to indoxacarb alone or in combination with deltamethrin (Fig. 7C). It is interesting to mention that prolonged exposition to deltamethrin $\left(10^{-6} \mathrm{M}\right) /$ indoxacarb $\left(10^{-6} \mathrm{M}\right)$ mixture than $72 \mathrm{~h}$ (i.e., $\left.96 \mathrm{~h}\right)$ did not produce any statistically significant higher mortality $(U(10,10)=38,5, p=0.38)(11 \pm 9 \%(n=10)$, $15 \pm 9 \%(n=10)$ for $72 h$ and $96 h$, respectively). To express more quantitatively the synergistic effect of LNC-deltamethrin on indoxacarb toxic activity, equation (3) was used to determine the combination index (see Materials and Methods section). As indicated in Table 2, the combined effect of LNC-deltamethrin $\left(10^{-6} \mathrm{M}\right) /$ indoxacarb $\left(10^{-6} \mathrm{M}\right)$ was greater than that predicted by their individual potencies and induced higher mortality than the mixture deltamethrin $\left(10^{-6} \mathrm{M}\right) /$ indoxacarb $\left(10^{-6} \mathrm{M}\right)$. For LNCdeltamethrin $\left(10^{-6} \mathrm{M}\right) /$ indoxacarb $\left(10^{-6} \mathrm{M}\right)$ combination, the combination index $(\mathrm{Cl})$ appeared 2.9-fold lower than that of deltamethrin $\left(10^{-6} \mathrm{M}\right) /$ indoxacarb $\left(10^{-6} \mathrm{M}\right)$. These results indicated that important synergistic interactions occurred between LNCdeltamethrin $\left(10^{-6} \mathrm{M}\right)$ and indoxacarb $\left(10^{-6} \mathrm{M}\right)$.

\subsection{Benefits of nanoencapsulation for the deltamethrin-induced synergistic effect}

The aim of the following experiments was to study in vitro (i) the contribution of esterases to deltamethrin degradation and (ii) how nanoencapsulation could help to protect deltamethrin against enzymatic degradation. Fig. 8A shows the percentage of deltamethrin detected in solution, plotted versus time. In this case, $99 \%$ of deltamethrin nanoencapsulated was detected in solution after $24 \mathrm{~h}$ of esterase 
treatment whereas only $40 \%$ of deltamethrin alone was found. These results clearly demonstrated the preservation effect of nanoencapsulation from enzymatic action.

In addition, the benefits of LNC-deltamethrin $\left(10^{-6} \mathrm{M}\right) /$ indoxacarb $\left(10^{-6} \mathrm{M}\right)$ in combination was evaluated, in vivo, in comparison to deltamethrin (10-6 M) / PBO / indoxacarb $\left(10^{-6} \mathrm{M}\right)$ mixture after $48 \mathrm{~h}$ and $72 \mathrm{~h}$ treatment (Fig. $\left.8 \mathrm{~B}\right)$. At both $48 \mathrm{~h}$ and 72h, mortality rates were significantly higher with the mixture LNC-deltamethrin (10$\left.{ }^{6} \mathrm{M}\right)$ / indoxacarb $\left(10^{-6} \mathrm{M}\right)(\mathrm{U}(10,10)=9.5, \mathrm{p}=0.0019$; and $\mathrm{U}(9,10)=13.5, \mathrm{p}=0.0093$ at 48h and 72h, respectively) compared to deltamethrin (10-6 M) / PBO / indoxacarb (10${ }^{6} \mathrm{M}$ ) in combination (Fig. 8B). These results provided an in vivo proof-of-concept for using LNC-deltamethrin rather than PBO to optimize the effect of indoxacarb.

\section{Discussion}

4.1. Deltamethrin increases intracellular calcium concentration through the activation of reverse $\mathrm{Na} / \mathrm{Ca}$ exchange

Whereas there are similarities in the voltage-gated sodium channel modification induced by type I and type II pyrethroids, marked differences are nevertheless observed between the two types in terms of distinct intoxication syndromes, of the kinetics of the sodium current modulation [16, 33, 34] and intracellular calcium concentration changes (this study). The findings described here show that deltamethrin, a type II pyrethroid, elevates intracellular calcium concentration in isolated DUM neurons, whereas the type I pyrethroid, permethrin does not produce any intracellular calcium rise. Our study further shows that, to the contrary of permethrin, the deltamethrin-induced intracellular calcium concentration elevation facilitates higher sensitivity of voltage-gated sodium channel to DCJW. This confirms previous findings that revealed the potentiation of the effect of DCJW on sodium 
channels through the activation of the calcium-dependent signaling pathways (e.g., CaM-kinase II pathway) resulting from intracellular calcium rise [19]. One of the most interesting feature is the mechanism by which deltamethrin elevates intracellular calcium concentration. To our knowledge, this is the first example reporting the participation of the neuronal reverse $\mathrm{Na} / \mathrm{Ca}$ exchanger in intracellular calcium changes produced by deltamethrin. The $\mathrm{Na} / \mathrm{Ca}$ exchanger regulates intracellular concentration of calcium and sodium ions in the vertebrate as well as invertebrate nervous system in a relevant physiological mechanism that maintains cellular homeostasis $[35,36]$. The $\mathrm{Na} / \mathrm{Ca}$ exchange acts as a bidirectional transporter. When operating in the forward mode, it plays a key role in lowering intracellular calcium concentration by electrogenically exchanging one cytosolic calcium for three external sodium. The $\mathrm{Na} / \mathrm{Ca}$ exchange can also function in a reverse mode causing calcium influx by exchanging extracellular calcium for intracellular sodium. Conditions that favour reverse $\mathrm{Na} / \mathrm{Ca}$ exchange include positive membrane potential and increased intracellular sodium. Deltamethrin as type II pyrethroid, causes membrane depolarization and prolonged opening of voltage-gated sodium channels primarily by modifying deactivation and stabilizing the open state [16, 34, 37]. In this case, the deltamethrin-induced tail-currents associated with repolarization under voltage-clamp conditions reflect the prolonged opening of pyrethroid-modified sodium channels. The decay of tail current induced by deltamethrin is much slower than that of induced by type I pyrethroid [34]. In other words, deltamethrin inhibits the deactivation of sodium channels to a greater extent than, for instance permethrin, the type I pyrethroid. This quantitative difference in tail current decay kinetics between permethrin and deltamethrin could account for their different action on isolated DUM neuron intracellular calcium concentration. Furthermore, deltamethrin requires repeated 
depolarizations to induce detectable tail currents. In our case, isolated DUM neurons, known to generate beating pacemaker sodium-dependent action potentials [38] are, consequently, very sensitive to deltamethrin, which will preferably bind to the activated (i.e., open) state of sodium channels (Fig. 9A, step 1). All together, these effects of deltamethrin cause a large increase in intracellular sodium concentration. When cytosolic sodium is elevated, the $\mathrm{Na} / \mathrm{Ca}$ exchange can switch from forward to reverse mode bringing external calcium into the DUM neuron (Fig. 9A, step 2). This is confirmed by KB-R7943, known to be a selective inhibitor of the $\mathrm{Na} / \mathrm{Ca}$ exchanger operating in the reverse mode [39, 40], which blocks the deltamethrin-induced elevation of calcium concentration. The intracellular calcium rise (Fig. 9A, step 3) potentiates the inhibitory effect of DCJW, obtained at lower concentration, on insect sodium channels (Fig. 9A, step 4), as previously reported [19].

4.2. Deltamethrin used as synergistic agent to optimize the efficacy of DCJW and indoxacarb

Based on the results described above, the synergistic effect observed in vitro in the presence of mixture of deltamethrin / DCJW compared to DCJW applied alone highlights the participation of intracellular calcium concentration elevation, triggered by deltamethrin, in the increase of sodium channel sensitivity to insecticide. The deltamethrin / DCJW mixture synergistic effect reflects that the reduction of the DUM neuron inward sodium current amplitude observed with DCJW alone is strongly potentiated when deltamethrin is co-applied with DCJW [41]. This makes deltamethrin a suitable candidate to be used as synergistic agent able to produce intracellular calcium concentration changes, which increase sensitivity of membrane 
sodium channels targeted by insecticides, as already reported for other synergistic agent / insecticide used in combination [7, 42].

Therefore, we have also investigated in vivo the interaction between deltamethrin and indoxacarb (the pro-insecticide that undergoes bioactivation in insects to the metabolite, DCJW) $[32,43]$ by co-applying deltamethrin in the presence of increased concentration of indoxacarb versus time of exposure (24, 48 and $72 h$ ). The results obtained, which correlate well with the in vitro studies, indicate that the interaction between deltamethrin and indoxacarb is synergistic (e.g., at 72h), resulting in a significant increase of the mortality rate of Periplaneta americana. According to these ensemble outcomes, it is tempting to postulate that deltamethrininduced intracellular calcium rise occurring, via the mechanism described above (Fig. 9A,B, steps 1-4), may serve as an additional calcium-dependent effector to optimize the effect of DCJW, produced in vivo, which will thereby increase the synergism between deltamethrin and indoxacarb.

\subsection{Nanoencapsulation of deltamethrin improves the synergism between} deltamethrin and indoxacarb

More importantly, we have developped nanocapsules carrying deltamethrin system as a promizing strategy to optimize indoxacarb efficacy while shortening time of exposure and reducing concentration of insecticides. Today, the potential use of nanoencapsulated insecticides and benefits are important and well known [21, 44]. Therefore, nanoencapsulation would provide efficient alternatives for the management used in agriculture and for the reduction of neurotoxic adverse effects on non-target animals. In our study, we propose the use of a new type of formulation including the nanoencapsulation of the synergistic agent (i.e., deltamethrin) 
combined with the non-nanencapsulated insecticide, indoxacarb. One of the more important problems with pyrethroids and particularly deltamethrin is that insects may detoxify or destroy the pyrethroid by the over-production of detoxifying enzymes (e.g., esterases) [45]. In this case, the pyrethroid-hydrolyzing esterase is able to catalyze the hydrolysis of deltamethrin in nontoxic and/or non-active compound. To counteract this problem, the development of nanoencapsulated deltamethrin (Fig. 9B) protects the synergistic agent from premature esterase degradation, as it has been demonstrated in our study, in vitro. This formulation could help to obtain a slow release of deltamethrin, used as synergistic agent, essential to trigger intracellular calcium rise involved in the potentiation of the effect of indoxacarb (bioactivated in DCJW), on voltage-gated sodium channels (Fig. 9B, step 5a). We also report that nanoencapsulation of the synergistic agent seems to provide an important technology in insecticide formulation compared with conventional insecticide formulation that include synergists such as PBO. Indeed comparative studies of mortality rate performed with deltamethrin combined with PBO and nanoencapsulated deltamethrin clearly reveal, in the last case, higher potentiation of indoxacarb efficiency. Furthermore, another advantage of the slow release of nanoencapsulated deltamethrin is that indoxacarb, which is only weakly active against insect voltage-gated sodium channels needs to be $\mathrm{N}$-decarbomethoxylated to DCJW, a metabolite and more potent sodium channel blocker [32]. This transformation being catalyzed by esterase/amidase enzymes, the slow release of deltamethrin used as synergistic agent will allow indoxacarb sufficient time to be bioactivated in DCJW to produce higher effect but at lower concentrations.

\section{Conclusions}


This study reports the development of new type of formulation that includes two active substances having distinct mode of actions on insect voltage-gated sodium channels. The strategy proposed combines the well-known type II pyrethroid deltamethrin used, for the first time, as synergistic agent and the oxadiazine insecticide indoxacarb. We have shown that unusual calcium-dependent mechanism underlying the action of deltamethrin might be essential in potentiating the inhibition of the sodium current induced by DCJW. The relatively low concentration of nanoencapsulated deltamethrin is also efficient to optimize the effect of indoxacarb / DCJW on sodium channels, while reducing concentration of indoxacarb. Finally in our case, the synergistic effect obtained with nanoencapsulated deltamethrin is more important than that of observed with conventional formulation that combined deltamethrin and PBO. Consequently, this type of formulation shows great promise as a mixture used against pest insects.

\section{Acknowledgements}

JPC is supported by the National Secretariat of Science, Technology and Innovation (SENACYT), Government Authority of the Republic of Panama (contract number: 270-2015-003). Part of this work was supported by funding from Merck Animal Health, Madison, USA. 


\section{References}

[1] J.E. Casida, Pesticide Interactions: Mechanisms, Benefits, and Risks, J. Agric. Food Chem. 65 (2017) 4553-4561.

[2] J.E. Casida, K.A. Durkin, Neuroactive insecticides: targets, selectivity, resistance, and secondary effects, Annu. Rev. Entomol. 58 (2013) 99-117.

[3] T.C. Sparks, R. Nauen, IRAC: Mode of action classification and insecticide resistance management, Pestic. Biochem. Physiol. 121 (2015) 122-128.

[4] F. Darriet, F. Chandre, Efficacy of six neonicotinoid insecticides alone and in combination with deltamethrin and piperonyl butoxide against pyrethroid-resistant Aedes aegypti and Anopheles gambiae (Diptera: Culicidae), Pest Manag. Sci. 69 (2013) 905-910.

[5] R. N'Guessan, V. Corbel, J. Bonnet, A. Yates, A. Asidi, P. Boko, A. Odjo, M. Akogbeto, M. Rowland, Evaluation of indoxacarb, an oxadiazine insecticide for the control of pyrethroid-resistant Anopheles gambiae (Diptera: Culicidae), J. Med. Entomol. 44 (2007) 270-276.

[6] R.M. Oxborough, R. N'Guessan, J. Kitau, P.K. Tungu, D. Malone, F.W. Mosha, M.W. Rowland, A new class of insecticide for malaria vector control: evaluation of mosquito nets treated singly with indoxacarb (oxadiazine) or with a pyrethroid mixture against Anopheles gambiae and Culex quinquefasciatus, Malaria Journal 14 (2015) 353.

[7] V. Raymond, D. Goven, Y. Benzidane, O. List, B. Lapied, Influence of Cellular and Molecular Factors on Membrane Target Sensitivity to Insecticides, Curr. Med. Chem. 24 (2017) 2974-2987.

[8] B. Saddiq, M. Ejaz, S.A. Shad, M. Aslam, Assessing the combined toxicity of conventional and newer insecticides on the cotton mealybug Phenacoccus solenopsis, Ecotoxicology 26 (2017) 1240-1249.

[9] X. Chen, M. Tie, A. Chen, K. Ma, F. Li, P. Liang, Y. Liu, D. Song, X. Gao, Pyrethroid resistance associated with M918 L mutation and detoxifying metabolism in Aphis gossypii from Bt cotton growing regions of China, Pest Manag. Sci. 73 (2017) 2353-2359.

[10] H.A. Khan, W. Akram, S.A. Shad, J.J. Lee, Insecticide mixtures could enhance the toxicity of insecticides in a resistant dairy population of Musca domestica L [corrected], PloS one, 8 (2013) e60929.

[11] F. Nikpour, H. Vatandoost, A.A. Hanafi-Bojd, A. Raeisi, M. Ranjbar, A.A. Enayati, M.R. Abai, M. Shayeghi, A.R. Mojahedi, A. Pourreza, Evaluation of Deltamethrin in Combination of Piperonyl Butoxide (PBO) against Pyrethroid Resistant, Malaria Vector, Anopheles stephensi in IRS Implementation: an Experimental Semi-Filed Trial in Iran, J. Arthropod Borne Dis. 11 (2017) 469481.

[12] V. Apaire-Marchais, M. Ogliastro, F. Chandre, C. Pennetier, V. Raymond, B. Lapied, Virus and calcium: an unexpected tandem to optimize insecticide efficacy, Environ. Microbiol. Rep. 8 (2016) 168-178.

[13] P. Licznar, O. List, D. Goven, R.N. Nna, B. Lapied, V. Apaire-Marchais, A novel method using Autographa californica multiple nucleopolyhedrovirus for increasing the sensitivity of insecticide through calcium influx in insect cell line, J. Virol. Met. 195 (2014) 72-75.

[14] S.D. Buckingham, M. Ihara, D.B. Sattelle, K. Matsuda, Mechanisms of Action, Resistance and Toxicity of Insecticides Targeting GABA Receptors, Current medicinal chemistry, 24 (2017) 29352945.

[15] R.H. Ffrench-Constant, M.S. Williamson, T.G. Davies, C. Bass, Ion channels as insecticide targets, J. Neurogenet. 30 (2016) 163-177.

[16] L.M. Field, T.G. Emyr Davies, A.O. O'Reilly, M.S. Williamson, B.A. Wallace, Voltage-gated sodium channels as targets for pyrethroid insecticides, Eur. Biophys. J. 46 (2017) 675-679.

[17] M. Ihara, S.D. Buckingham, K. Matsuda, D.B. Sattelle, Modes of Action, Resistance and Toxicity of Insecticides Targeting Nicotinic Acetylcholine Receptors, Curr. Med. Chem. 24 (2017) 2925-2934.

[18] B. Bodereau-Dubois, O. List, D. Calas-List, O. Marques, P.Y. Communal, S.H. Thany, B. Lapied, Transmembrane potential polarization, calcium influx, and receptor conformational state 
modulate the sensitivity of the imidacloprid-insensitive neuronal insect nicotinic acetylcholine receptor to neonicotinoid insecticides, J. Pharmacol. Exp. Ther. 341 (2012) 326-339.

[19] C. Lavialle-Defaix, B. Moignot, C. Legros, B. Lapied, How does calcium-dependent intracellular regulation of voltage-dependent sodium current increase the sensitivity to the oxadiazine insecticide indoxacarb metabolite decarbomethoxylated JW062 (DCJW) in insect pacemaker neurons?, J. Pharmacol. Exp. Ther. 333 (2010) 264-272.

[20] L. Murillo, A. Hamon, Z. Es-Salah-Lamoureux, V. Itier, S. Quinchard, B. Lapied, Inhibition of protein kinase $C$ decreases sensitivity of GABA receptor subtype to fipronil insecticide in insect neurosecretory cells, Neurotoxicology 32 (2011) 828-835.

[21] M. Nuruzzaman, M.M. Rahman, Y. Liu, R. Naidu, Nanoencapsulation, Nano-guard for Pesticides: A New Window for Safe Application, Journal of agricultural and food chemistry, 64 (2016) 14471483.

[22] B. Lapied, C.O. Malécot, M. Pelhate, lonic species involved in the electrical activity of single aminergic neurons isolated from the sixth abdominal ganglion of the cockroach Periplaneta americana, J. Exp. Biol. 144 (1989) 535-549.

[23] B. Lapied, H. Le Corronc, B. Hue, Sensitive nicotinic and mixed nicotinic-muscarinic receptors in insect neurosecretory cells, Brain Research, 533 (1990) 132-136.

[24] C. Lavialle-Defaix, H. Gautier, A. Defaix, B. Lapied, F. Grolleau, Differential regulation of two distinct voltage-dependent sodium currents by group III metabotropic glutamate receptor activation in insect pacemaker neurons, J. Neurophysiol. 96 (2006) 2437-2450.

[25] I.M. Chakravarti, R.G. Laha, J. Roy, Handbook of Methods of Applied Statistics, 1967.

[26] G. Bastiat, C.O. Pritz, C. Roider, F. Fouchet, E. Lignieres, A. Jesacher, R. Glueckert, M. RitschMarte, A. Schrott-Fischer, P. Saulnier, J.P. Benoit, A new tool to ensure the fluorescent dye labeling stability of nanocarriers: a real challenge for fluorescence imaging, J. Control. Release 170 (2013) 334-342.

[27] B. Heurtault, P. Legrand, V. Mosqueira, J.P. Devissaguet, G. Barratt, C. Bories, The antileishmanial properties of surface-modified, primaquine-loaded nanocapsules tested against intramacrophagic Leishmania donovani amastigotes in vitro, Ann. Trop. Med. Parasitol. 95 (2001) 529-533.

[28] B. Heurtault, P. Saulnier, B. Pech, J.E. Proust, J.P. Benoit, A novel phase inversion-based process for the preparation of lipid nanocarriers, Pharmaceutical Research 19 (2002) 875-880.

[29] T.C. Chou, P. Talalay, Quantitative analysis of dose-effect relationships: the combined effects of multiple drugs or enzyme inhibitors, Adv. Enzyme Regul. 22 (1984) 27-55.

[30] K.S. Silver, Y. Du, Y. Nomura, E.E. Oliveira, V.L. Salgado, B.S. Zhorov, K. Dong, Voltage-Gated Sodium Channels as Insecticides Targets, Adv In Insect Phys. 46 (2014) 45.

[31] B. Lapied, F. Grolleau, D.B. Sattelle, Indoxacarb, an oxadiazine insecticide, blocks insect neuronal sodium channels, Br. J. Pharmacol. 132 (2001) 587-595.

[32] K. Silver, K. Dong, B.S. Zhorov, Molecular Mechanism of Action and Selectivity of Sodium Ch annel Blocker Insecticides, Curr. Med. Chem. 24 (2017) 2912-2924.

[33] T.G. Davies, L.M. Field, P.N. Usherwood, M.S. Williamson, DDT, pyrethrins, pyrethroids and insect sodium channels, IUBMB life 59 (2007) 151-162.

[34] D.M. Soderlund, Molecular mechanisms of pyrethroid insecticide neurotoxicity: recent advances, Arch. Toxicol. 86 (2012) 165-181.

[35] L. Annunziato, G. Pignataro, G.F. Di Renzo, Pharmacology of brain $\mathrm{Na}^{+} / \mathrm{Ca}^{2+}$ exchanger: from molecular biology to therapeutic perspectives, Pharmacological Reviews 56 (2004) 633-654.

[36] L. Halty-deLeon, B.S. Hansson, D. Wicher, The Drosophila melanogaster $\mathrm{Na}(+) / \mathrm{Ca}(2+)$ Exchanger CALX Controls the $\mathrm{Ca}(2+)$ Level in Olfactory Sensory Neurons at Rest and After Odorant Receptor Activation, Front. Cell. Neurosci. 12 (2018) 186.

[37] T.J. Shafer, D.A. Meyer, Effects of pyrethroids on voltage-sensitive calcium channels: a critical evaluation of strengths, weaknesses, data needs, and relationship to assessment of cumulative neurotoxicity, Toxicol. Appl. Pharmacol. 196 (2004) 303-318. 
[38] F. Grolleau, B. Lapied, Dorsal unpaired median neurones in the insect central nervous system: towards a better understanding of the ionic mechanisms underlying spontaneous electrical activity, J. Exp. Biol. 203 (2000) 1633-1648.

[39] T. Brustovetsky, M.K. Brittain, P.L. Sheets, T.R. Cummins, V. Pinelis, N. Brustovetsky, KB-R7943, an inhibitor of the reverse $\mathrm{Na}^{+} / \mathrm{Ca}^{2+}$ exchanger, blocks $\mathrm{N}$-methyl-D-aspartate receptor and inhibits mitochondrial complex I, Br. J. Pharmacol., 162 (2011) 255-270.

[40] T. Iwamoto, T. Watano, M. Shigekawa, A novel isothiourea derivative selectively inhibits the reverse mode of $\mathrm{Na}^{+} / \mathrm{Ca}^{2+}$ exchange in cells expressing NCX1, J. Biol. Chem. 271 (1996) 2239122397.

[41] A. Flochlay-Sigognault, F. Guerino, B. Lapied, Parasiticidal combination comprising indoxacarb and deltamethrin, Patent number US 20140170199, E. I. Du Pont De Nemours And Company, 2014.

[42] C. Deshayes, E. Moreau, J. Pitti-Caballero, J.A. Froger, V. Apaire-Marchais, B. Lapied, Synergistic agent and intracellular calcium, a successful partnership in the optimization of insecticide efficacy, Curr. Opin. Insect Sci. 30 (2018) 52-58.

[43] R.T. von Stein, K.S. Silver, D.M. Soderlund, Indoxacarb, Metaflumizone, and Other Sodium Channel Inhibitor Insecticides: Mechanism and Site of Action on Mammalian Voltage-Gated Sodium Channels, Pestic. Biochem. Physiol. 106 (2013) 101-112.

[44] R. Prasad, A. Bhattacharyya, Q.D. Nguyen, Nanotechnology in Sustainable Agriculture: Recent Developments, Challenges, and Perspectives, Front. Microbiol. 8 (2017) 1014.

[45] M.A. Sogorb, E. Vilanova, Enzymes involved in the detoxification of organophosphorus, carbamate and pyrethroid insecticides through hydrolysis, Toxicol. Lett. 128 (2002) 215-228. 


\section{Figure legends}

Fig.1. The chemical structure of the pyrethroid insecticides deltamethrin (A) and permethrin (B) are shown together with structures of the oxadiazine insecticide indoxacarb $\left(\mathrm{R}=\mathrm{COOCH}_{3}\right)$ and the decarbomethoxylated JW062 (R = H; DCJW) (C).

Fig.2. Effects of deltamethrin and permethrin on intracellular calcium concentration in Fura-2 loaded isolated DUM neuron cell bodies. (A) Fura-2 fluorescence of a single DUM neuron cell body after bath application of deltamethrin $\left(10^{-6} \mathrm{M}\right)$ (a) and permethrin $\left(10^{-6} \mathrm{M}\right)(\mathrm{b})$. Images shown were acquired $200 \mathrm{sec}, 450 \mathrm{sec}$ and $700 \mathrm{sec}$ after the start of insecticide exposures. (B) Intracellular calcium concentration variations were plotted as a function of time of deltamethrin (red) and permethrin (black) treatments. Note that only deltamethrin $\left(10^{-6} \mathrm{M}\right)$ triggered an intracellular calcium rise in isolated DUM neuron cell body. Scale bar, $50 \mu \mathrm{m}$.

Fig.3. Deltamethrin-induced intracellular calcium rise in Fura-2 loaded isolated DUM neuron cell body. (A) Pretreatment with the inorganic calcium channel blocker $\mathrm{CdCl}_{2}$ $\left(5.10^{-4} \mathrm{M}\right)$ did not produce any effect on the intracellular calcium concentration elevation produced by deltamethrin $\left(10^{-6} \mathrm{M}\right)(\mathrm{a}, \mathrm{b}$; red). By contrast, pretreatment with the sodium channel blocker tetrodotoxin (TTX, 10-7 M) (a) and by Kb-R7943 $\left(5.10^{-6} \mathrm{M}\right)$ (b), an inhibitor of the reverse $\mathrm{Na}^{+} / \mathrm{Ca}^{2+}$ exchanger completely abolished the deltamethrin-induced intracellular calcium rise (black). (B) Three-dimensional spatiotemporal models of Fura-2 fluorescence of a single DUM neuron cell body after application of deltamethrin $\left(10^{-6} \mathrm{M}\right)$ obtained under different experimental conditions as indicated in (a), (b) and (c). 
Fig.4. Synergistic effect produced by deltamethrin on the DCJW-induced inhibition of the sodium current. (A) Comparative histogram of the percentage of inhibition of the sodium current amplitude after 20 minutes of treatment with permethrin $\left(10^{-5} \mathrm{M}\right)$ alone $(n=4)$, DCJW $\left(10^{-7} M\right)$ alone $(n=6)$ and with DCJW $\left(10^{-7} M\right)$ combined with permethrin $\left(10^{-5} M\right)(n=9)$. (B) Comparative histogram of the percentage of inhibition of the sodium current amplitude after 20 minutes of treatment with deltamethrin $\left(3.10^{-6} \mathrm{M}\right)$ alone $(n=5)$, DCJW $\left(10^{-7} M\right)$ alone $(n=6)$ and with DCJW $\left(10^{-7} M\right)$ combined with deltamethrin $\left(3.10^{-6} M\right)(n=6)$. (C) Semi-logarithmic dose-response curve for the blockade of sodium current obtained after 20 minutes of treatment with deltamethrin $\left(3.10^{-6} \mathrm{M}\right.$ ) in combination with DCJW (from $10^{-10}$ to $\left.10^{-7} \mathrm{M}\right)(\mathrm{n}=6)$. Arrow indicates the concentration of deltamethrin used to obtain the synergistic effect. Data are means \pm S.E.M. Statistical test is one-way ANOVA, followed by post-hoc Bonferroni's test. ns (not significant) $p>0.05 ;{ }^{* *} p<0.01$.

Fig.5. Effects of deltamethrin on adult male cockroaches Periplaneta americana. Cockroaches were fed orally with $10 \mu \mathrm{L}$ of deltamethrin ranging from $10^{-7} \mathrm{M}$ to $10^{-4} \mathrm{M}$. Mortality rate was assessed $24 \mathrm{~h}(\mathrm{~A}), 48 \mathrm{~h}(\mathrm{~B})$ and $72 \mathrm{~h}(\mathrm{C})$ after intoxication. Between 60 and 100 cockroaches were used for each concentration. Smooth lines represent the best fit through the mean data according to the equation (2) (D-F) Histograms illustrating comparative effects of indoxacarb tested alone at $10^{-7} \mathrm{M}, 10^{-6} \mathrm{M}$ and $10^{-5} \mathrm{M}$ and indoxacarb associated with deltamethrin $\left(10^{-5} \mathrm{M}\right)$ or deltamethrin $\left(10^{-6} \mathrm{M}\right)$ at $24 \mathrm{~h}$ (D), 48h and $72 h(F)$. Data are means \pm S.E.M $(n=4-9)$. Statistical test is MannWhitney. ns (not significant) $p>0.05 ;{ }^{*} p<0,05 ;{ }^{* *} p<0.01$. 
Fig.6. Effects of deltamethrin and nanoencapsulated deltamethrin (LNC-deltamethrin) intoxications on adult male cockroaches Periplaneta americana. (A) Comparative histograms of the effects of sublethal concentration of LNC-deltamethrin $\left(10^{-5} \mathrm{M}\right)$ tested alone and deltamethrin $\left(10^{-5} \mathrm{M}\right)$ in combination with PBO (piperonyl butoxide; $50 \mu \mathrm{g} /$ cockroach) at $24 \mathrm{~h}, 48 \mathrm{~h}$ and $72 \mathrm{~h}$. (B-D) Superimposed semi-logarithmic concentration-response curves for the mortality rate produced by deltamethrin alone (grey) and LNC-deltamethrin (orange) at $24 \mathrm{~h}(\mathrm{~B}), 48 \mathrm{~h}(\mathrm{C})$ and $72 \mathrm{~h}(\mathrm{D})$, Smooth lines represent the best fit through the mean data according to the equation (2). Data are means \pm S.E.M $(n=4,17)$. Statistical test is Mann-Whitney. ns (not significant) $p>0.05 ;{ }^{*} p<0.05 ;{ }^{* \star} p<0.01 ;{ }^{* \star} p<0.001$.

Fig.7. Comparative histogram summarizing the mortality rate produced by LNCdeltamethrin $\left(10^{-6} \mathrm{M}\right)$ and deltamethrin $\left(10^{-6} \mathrm{M}\right)$ alone versus different concentrations of indoxacarb $\left(10^{-7} \mathrm{M}, 10^{-6} \mathrm{M}\right.$ and $\left.10^{-5} \mathrm{M}\right)$ on adult male cockroaches Periplaneta americana at $24 \mathrm{~h}(\mathrm{~A}), 48 \mathrm{~h}(\mathrm{~B})$ and $72 \mathrm{~h}(\mathrm{C})$. Data are means \pm S.E.M $(\mathrm{n}=5-10)$. Statistical test is Mann-Whitney. ns (not significant) $p>0.05 ;{ }^{*} p<0.05 ;{ }^{* *} p<0.01$. Mortality rate for "no deltamethrin" groups are only in the graphs as an indication.

Fig.8. Enzymatic protection of deltamethrin by nanoencapsulation. (A) In vitro deltamethrin hydrolysis. \% of deltamethrin in solution, loaded in LNC $(\bullet)$ or soluble in DMSO/water 1/49 $(v / v)(\square)$ versus time in presence of esterase $(0.009 \mathrm{U} / \mathrm{mL})$. Initial concentration of deltamethrin $95 \mu \mathrm{g} / \mathrm{mL}(\mathrm{n}=3$, mean $\pm S D)$. (B) Comparative effects of the mortality rate produced by the mixture LNC-deltamethrin $\left(10^{-6} \mathrm{M}\right) /$ indoxacarb $\left(10^{-}\right.$ $\left.{ }^{6} \mathrm{M}\right)$ versus deltamethrin $\left(10^{-6} \mathrm{M}\right)$ in combination with the enzymatic inhibitor PBO / 
indoxacarb $\left(10^{-6} \mathrm{M}\right)$ on adult male cockroaches Periplaneta americana at $48 \mathrm{~h}$ and 72h. Data are means \pm S.E.M $(n=4-10)$. Statistical test is Mann-Whitney. ${ }^{* *} p<0.01$. Mortality rate for "indoxacarb $\left(10^{-6} \mathrm{M}\right)$ " groups are only in the graph as an indication.

Fig. 9 Hypothetic pattern summarizing the strategy proposed to optimize the effect of DCJW (in vitro) and indoxacarb (in vivo) by deltamethrin used as a chemical synergistic agent. In isolated short-term cultured insect neurons (A), the modulation of voltage-gated sodium channels induced by deltamethrin (1) produces an increase in intracellular sodium concentration along with membrane depolarization, which thereby favors the influx of calcium via the $\mathrm{Na} / \mathrm{Ca}$ exchanger (reverse mode) (2). The resulting elevation of intracellular $\mathrm{Ca}^{2+}$ concentration (3) renders voltage-gated sodium channel more sensitive to lower concentration of DCJW (4). Nanoencapsulation (B) helps to protect deltamethrin, in vivo, from esterase-induced enzymatic degradation. Nevertheless, esterases are essential in the selective conversion of indoxacarb to DCJW (5). 
A

B<smiles>CC1(C)[C@@H](CC(Cl)Cl)[C@@H]1C(=O)OCc1cccc(Oc2ccccc2)c1</smiles><smiles>COC(=O)C1CN(C(=O)Nc2ccc(OC(C)(F)F)cc2)N=C2c3ccc(Cl)cc3CC21C(=O)OC</smiles>

Figure 1 


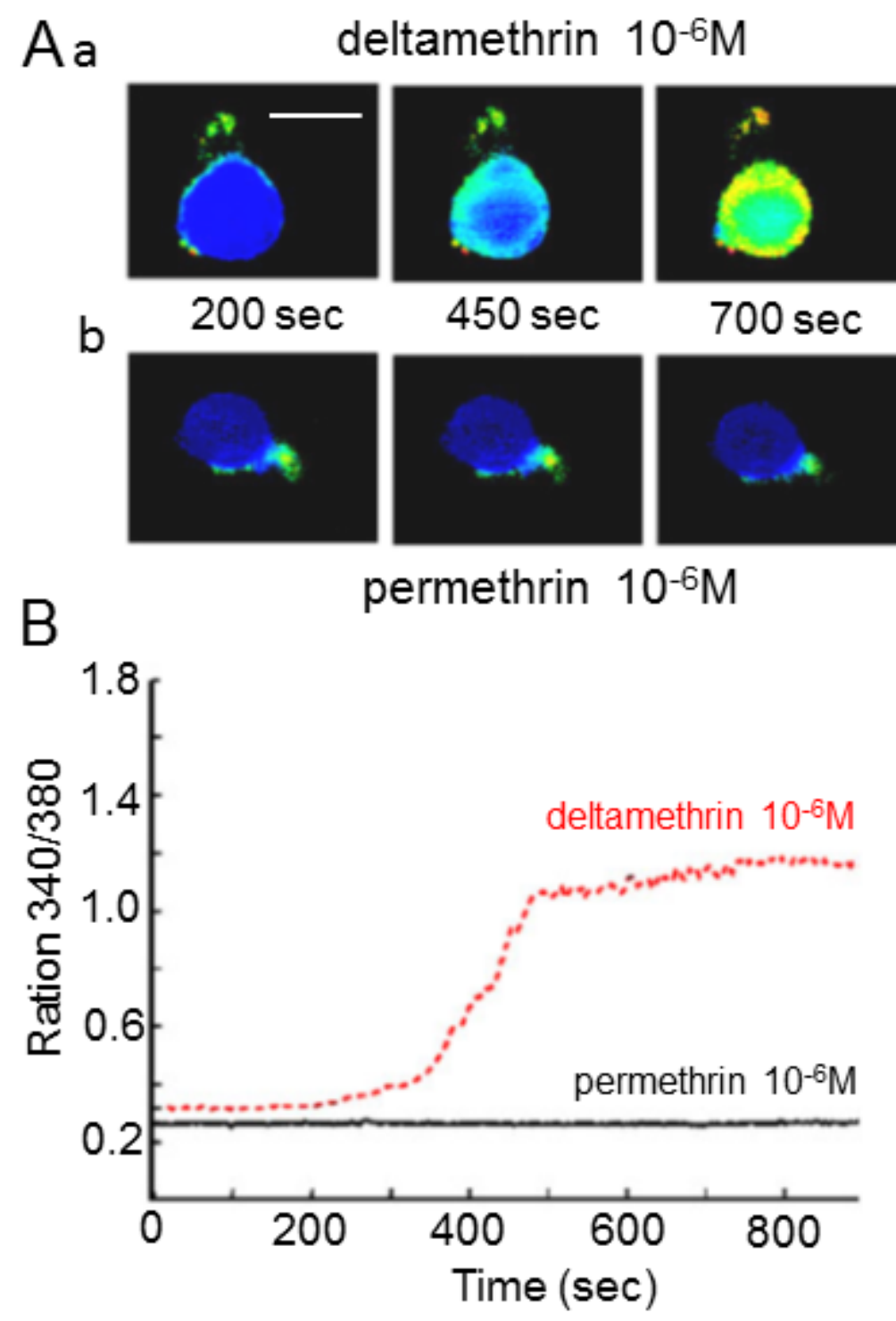

Figure 2 

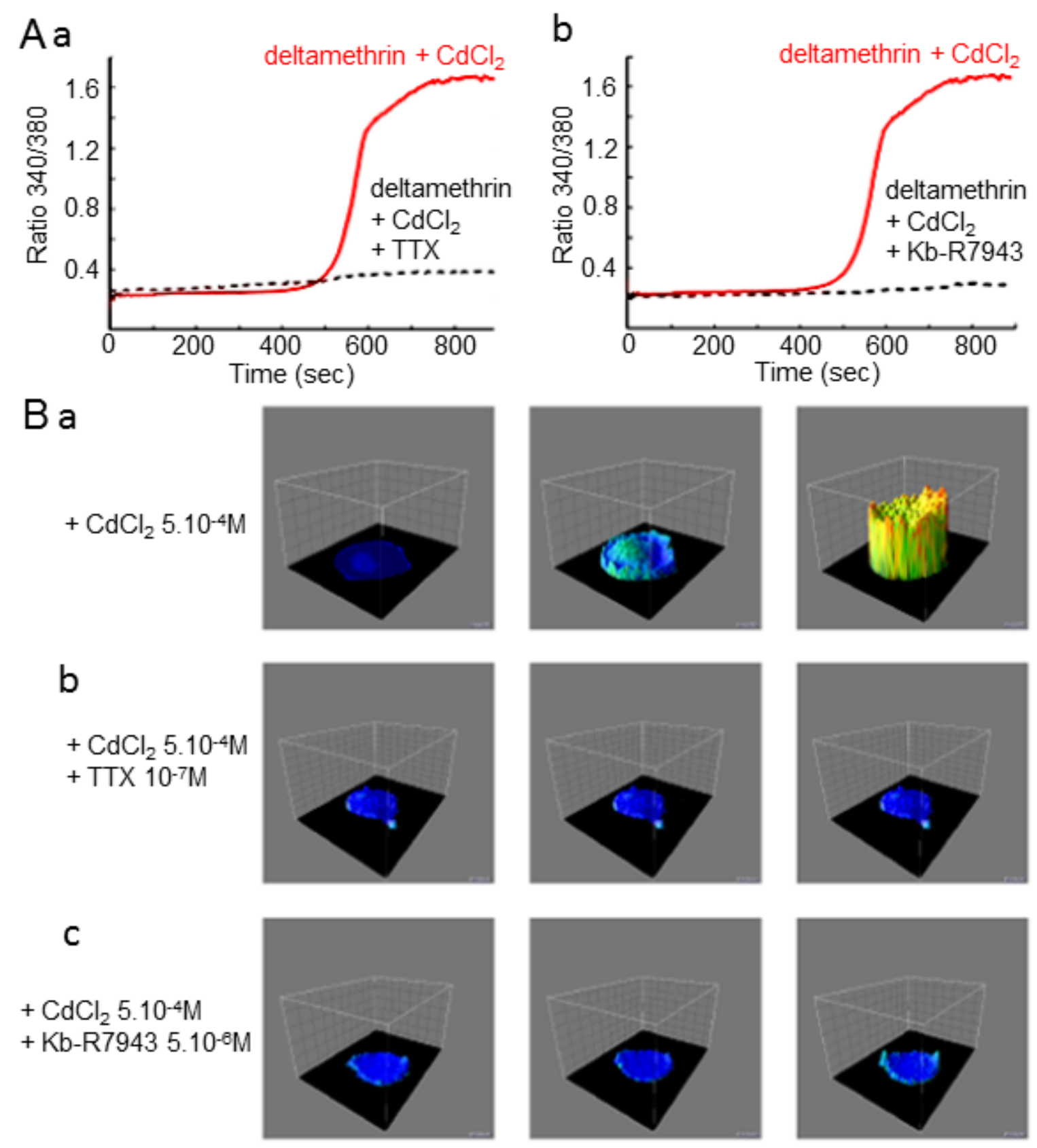

$500 \mathrm{sec}$

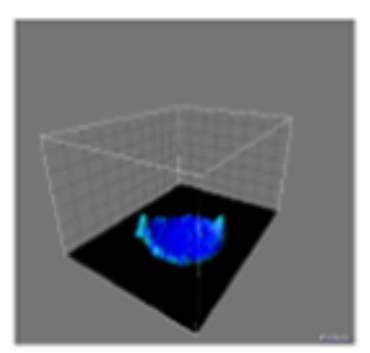

Figure 3 

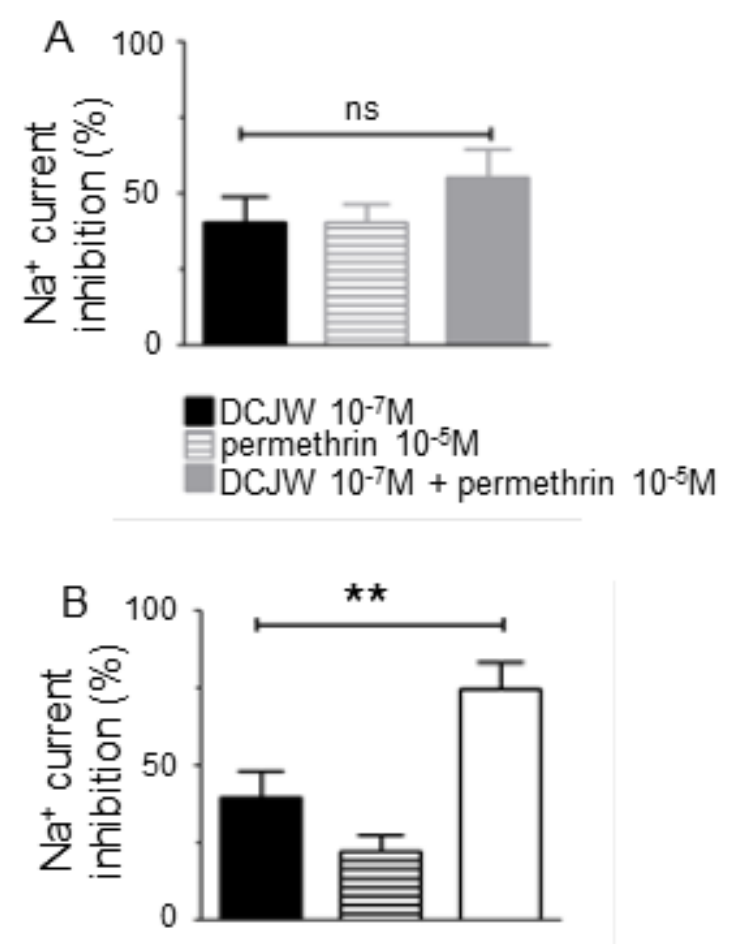

DCJW $10^{-7} \mathrm{M}$

deltamethrin $3 \cdot 10^{-6} \mathrm{M}$

DDCJW $10^{-7} \mathrm{M}$ + deltamethrin $3 \cdot 10^{-8} \mathrm{M}$

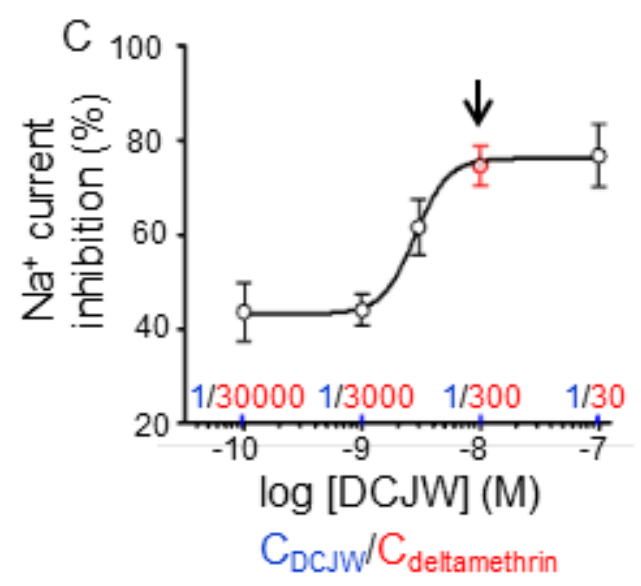

Figure 4 
A

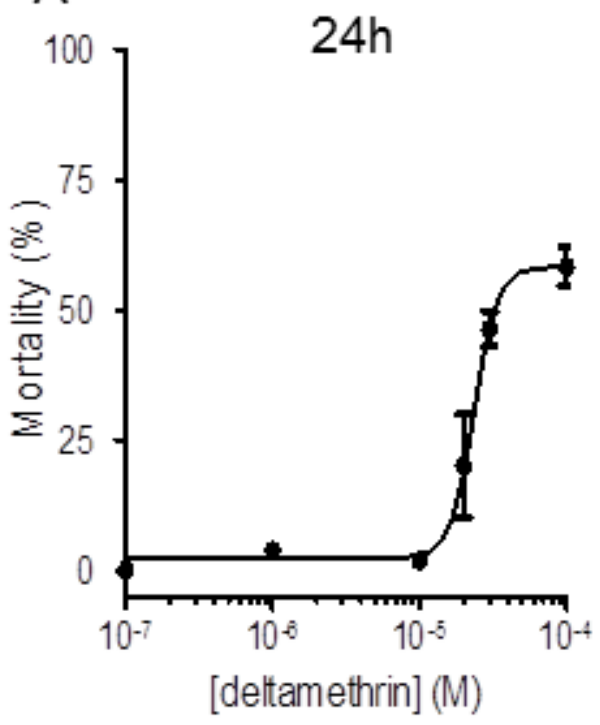

D

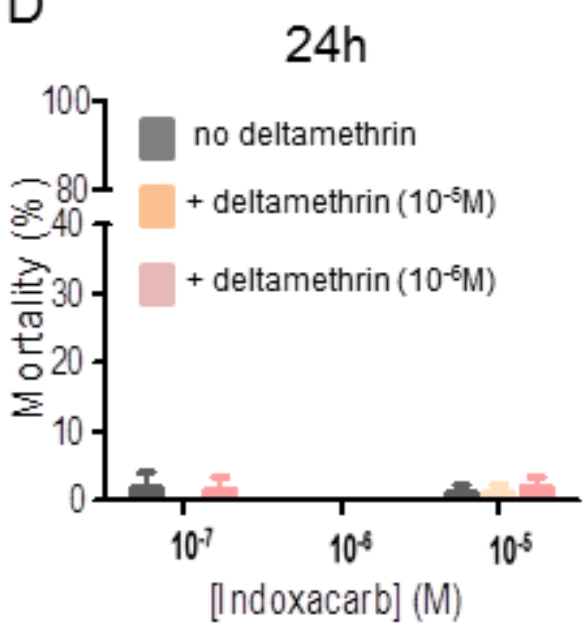

B

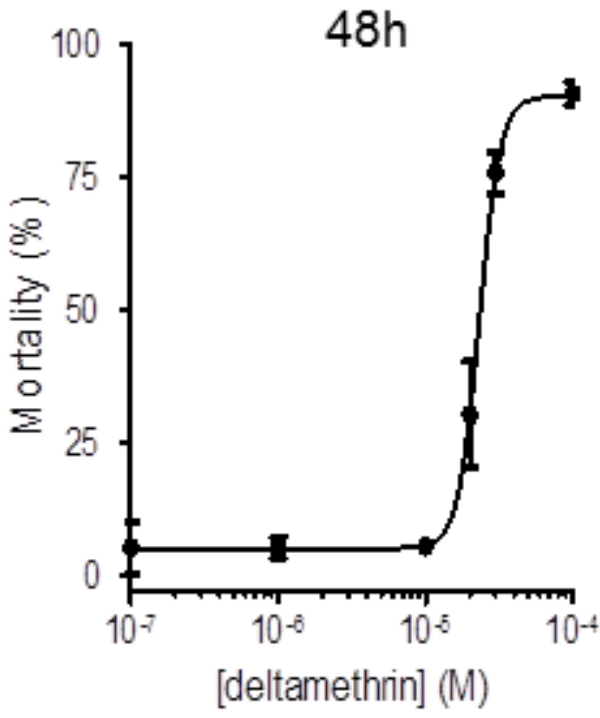

E

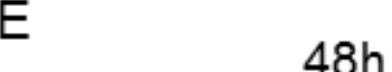

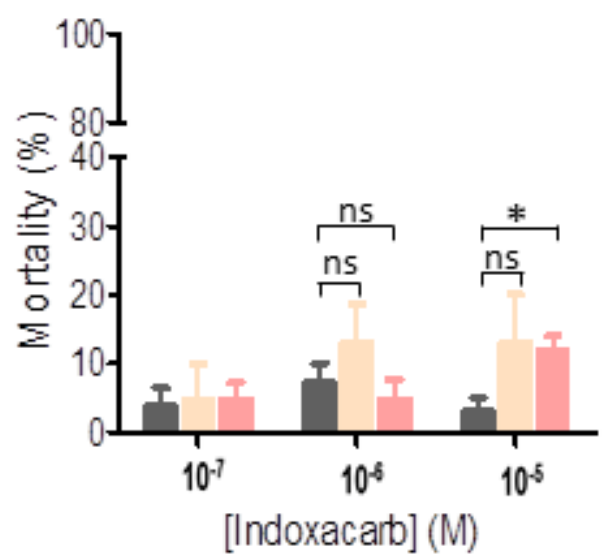

C

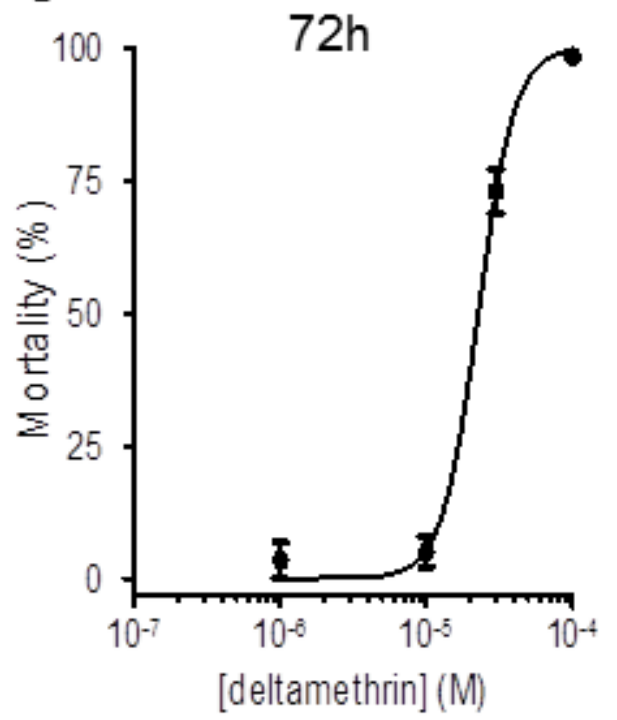

F $72 \mathrm{~h}$

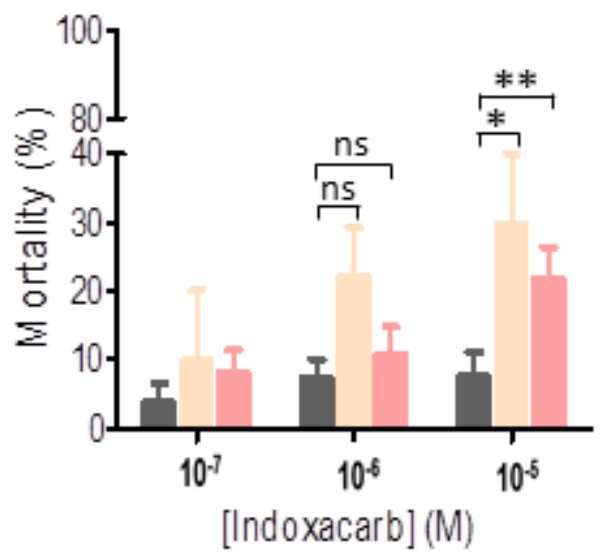

Figure 5 

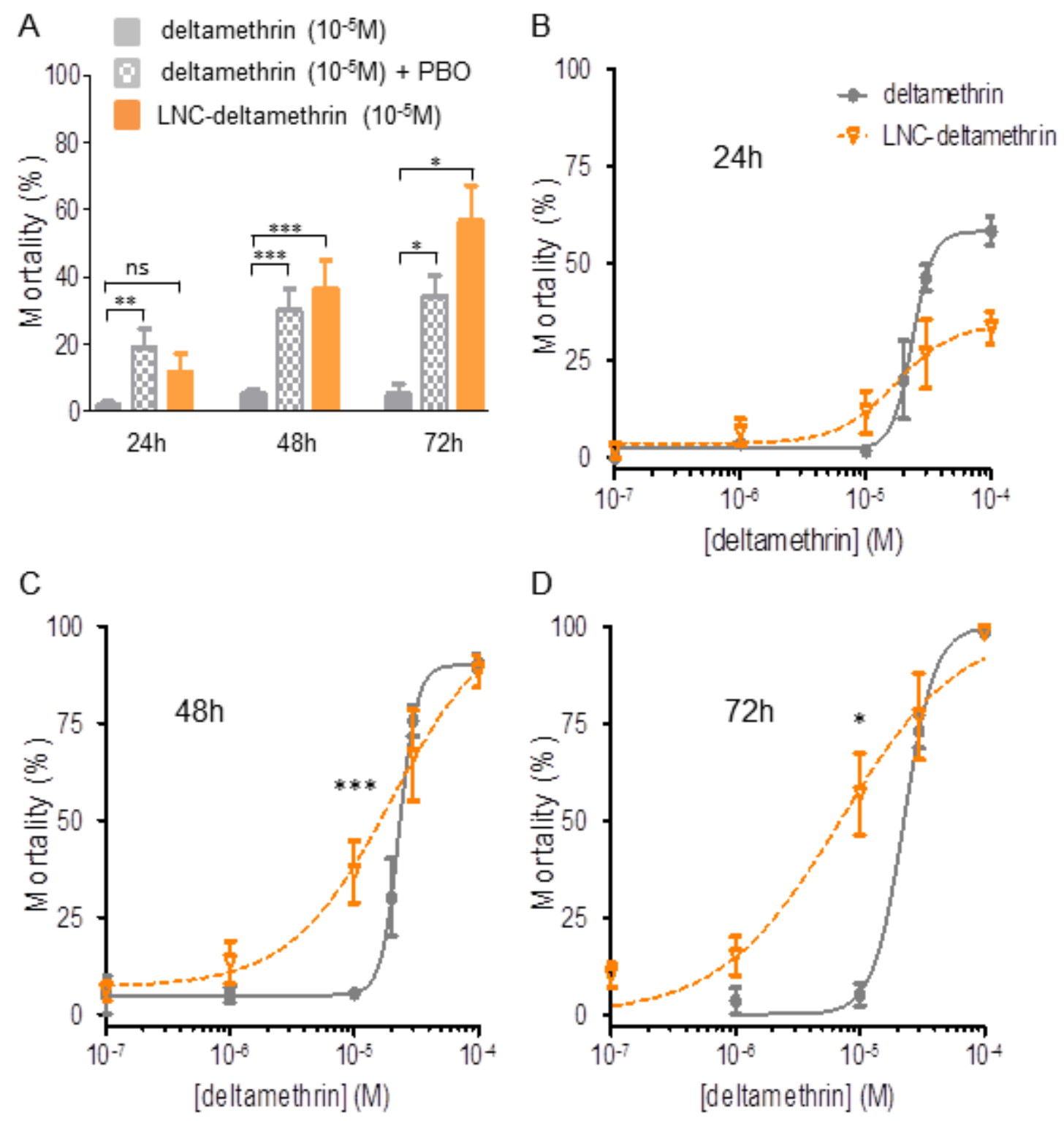

Figure 6 

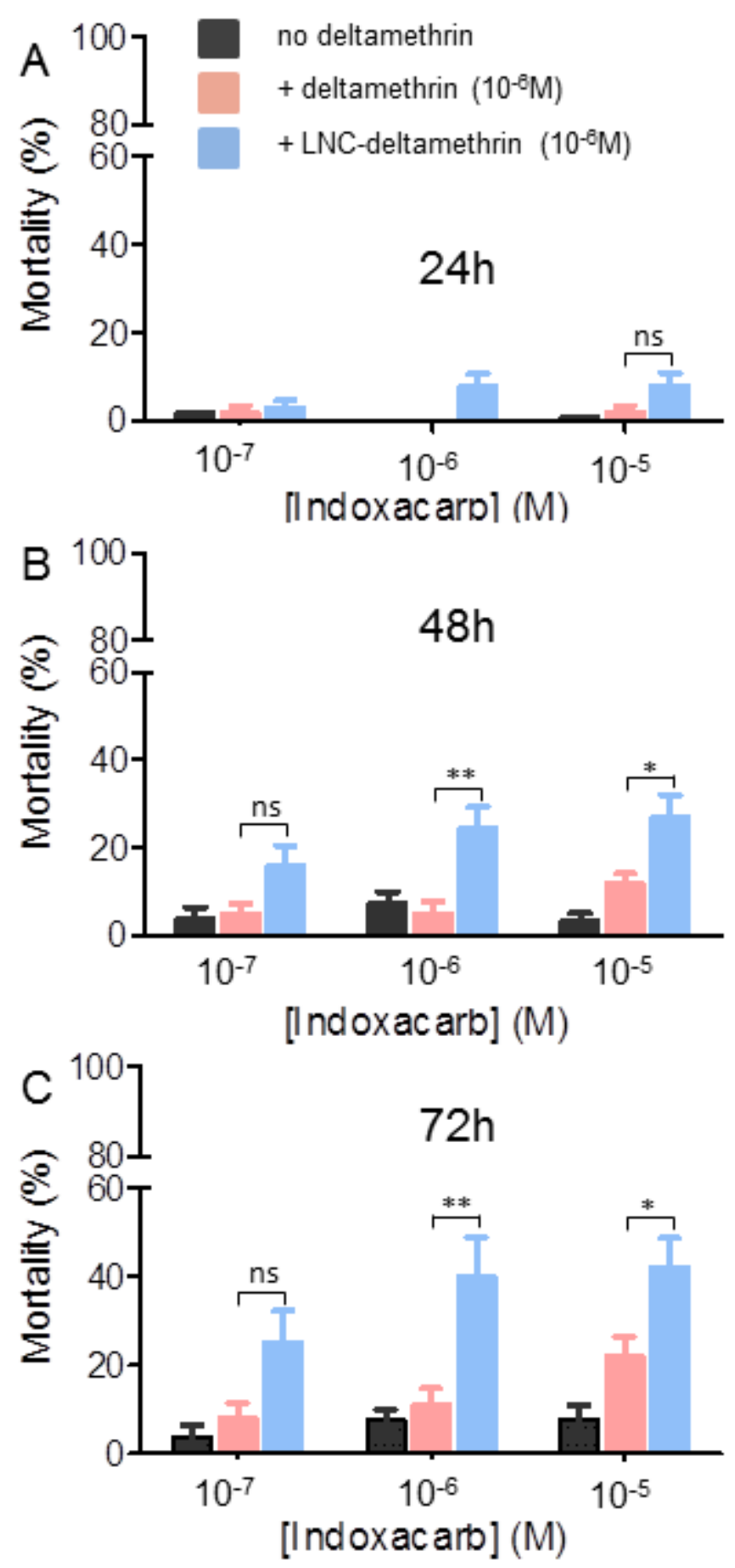

Figure 7 
A
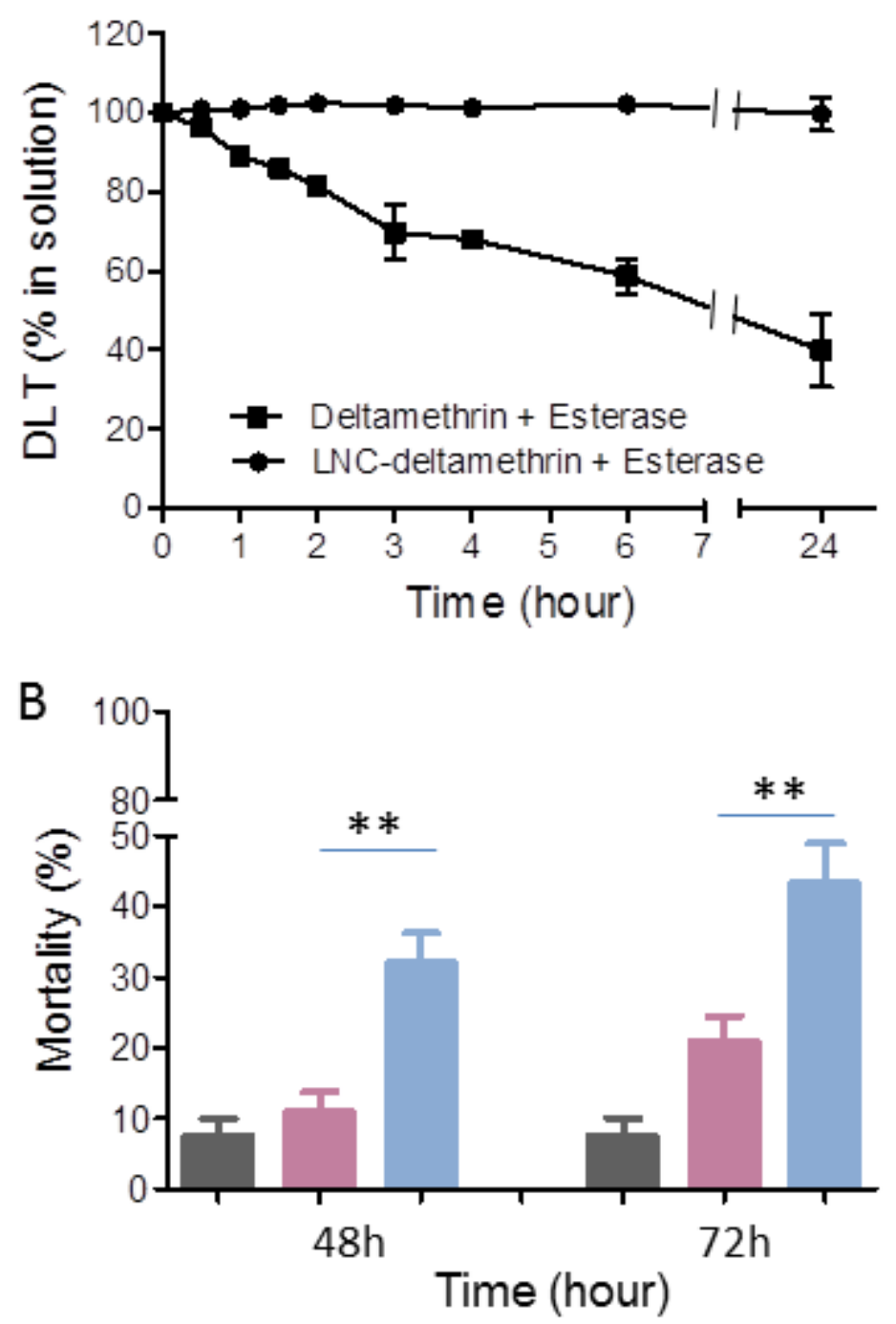

indoxacarb $\left(10^{-6} \mathrm{M}\right)$

deltamethrin $\left(10^{-6} \mathrm{M}\right)+\mathrm{PBO}+$ indoxacarb $\left(10^{-6} \mathrm{M}\right)$

LNC-deltamethrin $\left(10^{-6} \mathrm{M}\right)+$ indoxacarb $\left(10^{-6} \mathrm{M}\right)$

Figure 8 


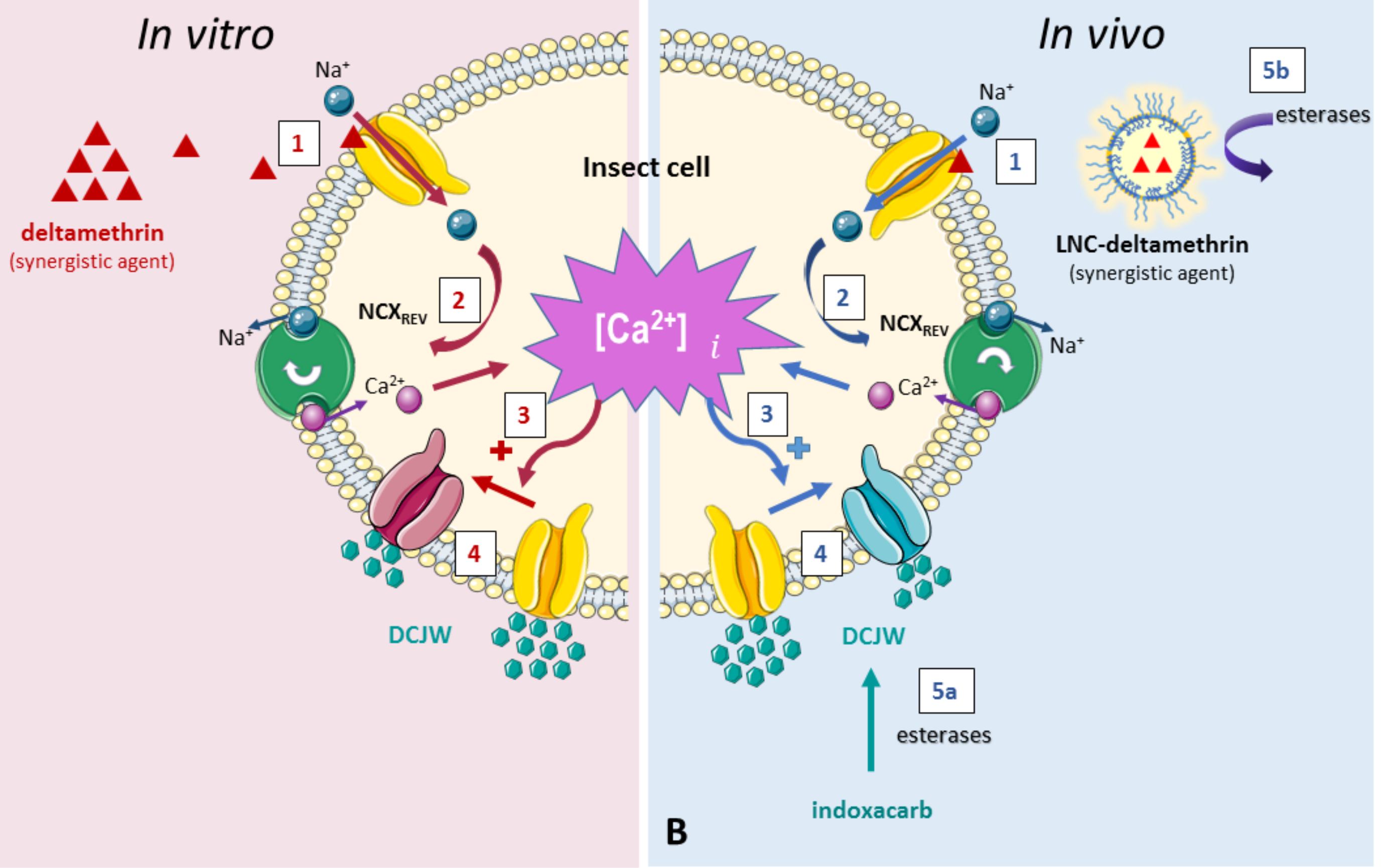

Figure 9 
Table 1: Parameters of the concentration-response curve established for deltamethrin after intoxication of adult male cockroaches Periplaneta americana

\begin{tabular}{cccc}
\hline & $\mathbf{2 4 h}$ & $\mathbf{4 8 h}$ & $\mathbf{7 2 h}$ \\
\hline $\mathrm{EC}_{50}(\mathrm{M})$ & $2.3510^{-5}$ & $2.3110^{-5}$ & $2.2610^{-5}$ \\
Hill slope & 5.40 & 6.09 & 3.50 \\
$\mathrm{R}^{2}$ & 0.85 & 0.94 & 0.97 \\
\hline
\end{tabular}


Table 2: Combination index values of insecticide mixtures against the cockroach Periplaneta americana after $72 \mathrm{~h}$ exposure

\begin{tabular}{|c|c|c|c|c|}
\hline $\begin{array}{c}\text { Insecticide } \\
\text { mixture } \\
(1+2)\end{array}$ & $\begin{array}{c}\text { [insecticide 1] } \\
\mathrm{LC}_{20}(\mathrm{M})(95 \% \mathrm{Cl})\end{array}$ & $\begin{array}{c}\text { [insecticide 2] } \\
\text { LC }_{20}(\mathrm{M})(95 \% \mathrm{Cl})\end{array}$ & $\begin{array}{c}\text { [insecticides } 1+2 \text { ] } \\
\text { LC }_{20}(\mathrm{M})(95 \% \mathrm{Cl})\end{array}$ & $\mathrm{Cl}^{\mathrm{a}}$ \\
\hline$D L T+I N D$ & $1.510^{-5}\left(1.210^{-5}-1.910^{-5}\right)$ & $1.710^{-4}\left(8.210^{-5}-3.410^{-4}\right)$ & $6.510^{-6}\left(2.210^{-6}-1.910^{-5}\right)$ & 0.49 \\
\hline LNC-DLT / IND & 1.5. $10^{-6}\left(5.910^{-7}-3.810^{-6}\right)$ & $1.710^{-4}\left(8.210^{-5}-3.410^{-4}\right)$ & $2.610^{-7}\left(5.310^{-8}-1.310^{-6}\right)$ & 0.17 \\
\hline
\end{tabular}

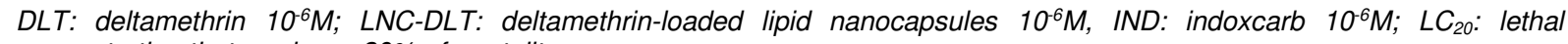
concentration that produces $20 \%$ of mortality

${ }^{a}$ Combination Index at $L C_{20}$ 


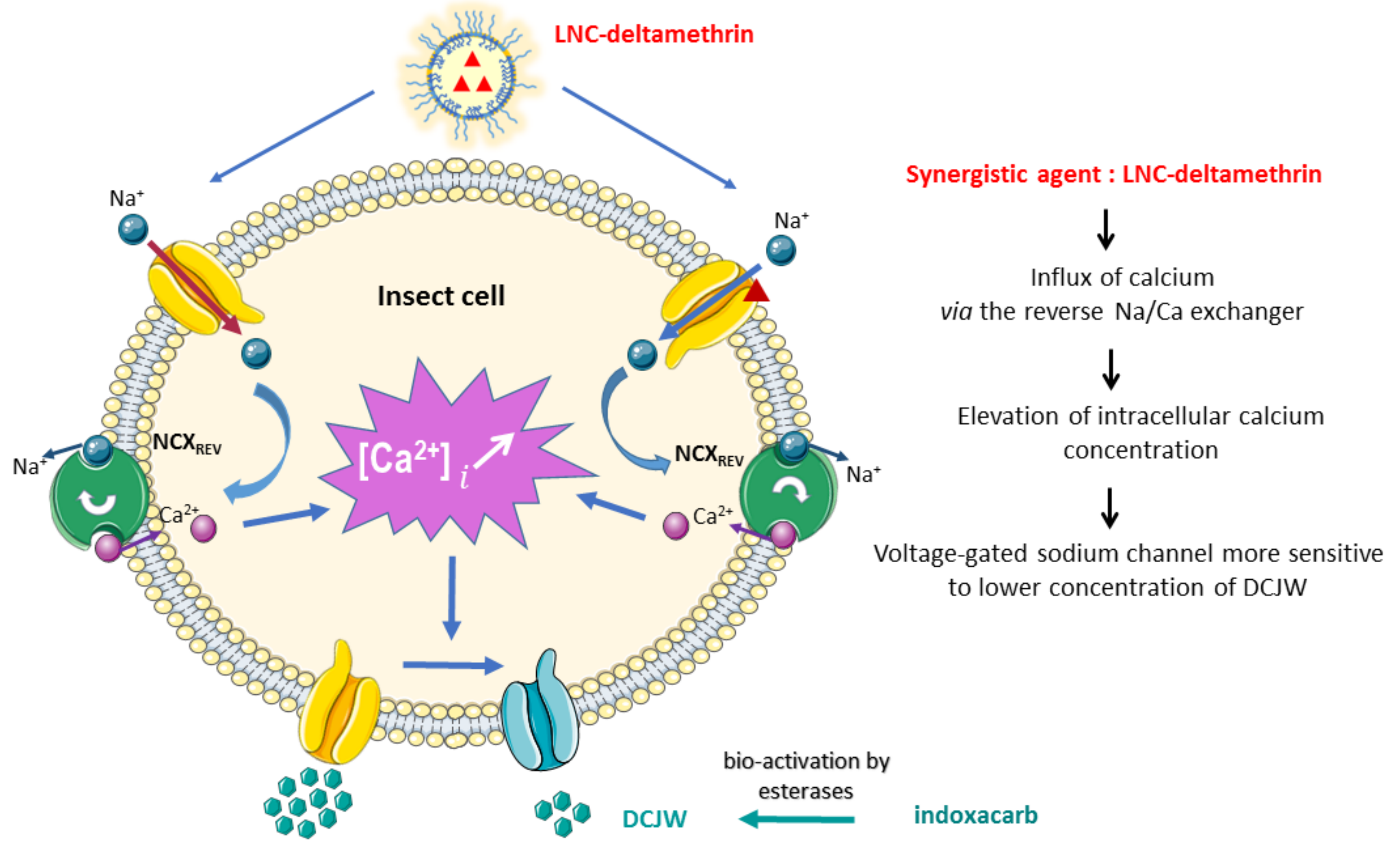

